\title{
Passive Aeroelastic Control of a Suspension Bridge during Erection
}

\author{
K. N. Bakis ${ }^{\mathrm{a}}$, D. J. N. Limebeer ${ }^{\mathrm{a}}$, M. S. Williams ${ }^{\mathrm{a}}$, J. M. R. Graham ${ }^{\mathrm{b}}$ \\ ${ }^{a}$ Department of Engineering Science, University of Oxford, Parks Road, Oxford OX1 3PJ, UK \\ ${ }^{b}$ Department of Aeronautics, Imperial College London, London SW7 2AZ, UK
}

\begin{abstract}
This study presents a system based on passively controlled leading- and trailing-edge flaps that is designed to suppress windinduced instabilities such as flutter and torsional divergence. The utility of the approach is demonstrated on a three-dimensional bridge model. Particular emphasis is placed on the early stages of the deck erection process when the bridge is particularly vulnerable to flutter. The flaps are activated by the deck's movements though passive phase-compensating mechanisms comprising of springs, dampers and inerters. It is demonstrated that optimised compensator parameters, and optimum hinge locations, result in a substantially improved deck aerodynamic performance. Particular importance is given to ensuring that the controlled system has good closed-loop 'robustness' properties, or in other words, that the controlled system has a high tolerance to parameter variations and uncertainties in the system dynamics. The practical use of a nonlinear optimization algorithms with a FE bridge aeroelastic model, which includes the flap dynamics, necessitates the use of reduced-order models. A novel model reduction procedure that is based on the retention of dominant poles is introduced into the aeroelastic modelling framework. Multimodal interactions are observed at the various erection stages and conclusions are drawn with regard to the contributions of various modes of vibration to aeroelastic instabilities. The main advantage of this approach lies on the passive system's simplicity and its ability to simultaneously increase the flutter and torsional divergence boundaries. The Humber Bridge in the U.K. is chosen as a study example for numerical simulations.
\end{abstract}

Keywords: Long-Span Bridges, Flutter Suppression, Passive Aerodynamic Robust Control, Erection Stage, Flaps, Humber Bridge

\section{Introduction}

It is now widely appreciated that long-span bridges are prone to aerodynamic instabilities, with the iconic Tacoma Narrows bridge disaster (1940) serving as a reminder of the importance of fluid-structure interaction phenomena. This failure was a result of the gradual growth of a flutter oscillation that lasted for approximately 45 minutes before the bridge's failure. The spectacular collapse was attributed to the use of a structurally and aerodynamically inappropriate squat H-section for the deck's girders [1]. Subsequent bridge designs, such as in the Tacoma Bridge rebuild (1950), made use of deep open-truss deck sections for increasing the bridge's torsional stiffness and enhancing its aerodynamic performance.

An alternative more contemporary approach is based on the use of streamlined flat box girders, a solution first adopted on the Severn Bridge (1966). Flat box girders offer adequate torsional rigidity, reduced wind drag, and provide a lighter alternative to the 'massy' deck truss section design [2]. Unlike deep trusses, flat box girders can be reasonably approximated aerodynamically as thin plates. Based on this premise, The work presented here makes use of Theodorsen's thin aerofoil theory $[3,4]$ to examine self-excited oscillatory flutter instabilities. This theory also exposes a non-oscillatory aerostatic instability known as torsional divergence. The torsional divergence mode is an aerodynamic mode that becomes unstable when there is an effective loss of torsional rigidity due to the cancellation of the (positive) torsional stiffness of the structure by a negative pitch-related aerodynamic moment [3]. 


\begin{tabular}{|c|c|c|}
\hline$A_{c}$ & $\left(m^{2}\right)$ & cable cross sectional area \\
\hline$A_{d}, A_{l}, A_{t}$ & $\left(m^{2}\right)$ & cross section areas of the deck, leading and trailing flaps respectively \\
\hline$A_{g}, E_{g}$ & () & state matrices of the generalized eigenvalue problem Eq.(14) \\
\hline$\tilde{A}, \tilde{B}, \tilde{C}, \tilde{D}$ & () & state space realization of the approximation of the Theodorsen function $C(s)$ \\
\hline$\tilde{A}_{g}, \tilde{B}_{g}, \tilde{C}_{g}, \tilde{D}_{g}$ & () & $\begin{array}{l}\text { Matrices containing state space realizations of the approximate Theodorsen } \\
\text { function for the } \mathrm{N} \text { elements of the FE structure }\end{array}$ \\
\hline$b$ & $(m)$ & half chord width of the deck \\
\hline$b$ & $\left(\mathrm{kgm}^{2} / \mathrm{m}\right)$ & inertance in the mechanical controller realization \\
\hline$b_{c}$ & $(m)$ & half distance between main cables \\
\hline$B, B_{g}$ & () & input matrices for the state space sectional and FE model representation \\
\hline$C(k)^{\circ}$ & () & Theodorsen function \\
\hline$c_{l} b, c_{t} b$ & $(m)$ & location of leading and trailing flap break points \\
\hline$C_{h}, C_{\alpha}$ & $(N s / m)$ & vertical and torsional bridge mode damping coefficient \\
\hline$C_{\beta}, C_{\gamma}$ & $(N s / m)$ & leading and trailing flap damping coefficients \\
\hline$C, C_{g}$ & & output matrices for the state space sectional and FE model representation \\
\hline$c_{1}, c_{2}$ & $\left(\frac{\text { Nmsec }}{\text { radm }}\right)$ & damper elements in the mechanical controller realization \\
\hline$d_{c}$ & $(m)$ & cable diameter \\
\hline$d_{f}$ & $(m)$ & flap plate thickness \\
\hline$E$ & $\left(N / m^{2}\right)$ & girder Young's modulus of elasticity \\
\hline$E_{c}$ & $\left(N / m^{2}\right)$ & cable Young's modulus of elasticity \\
\hline$E_{f}, A_{f}, B_{f}, C_{f}$ & () & state space representation of the uncontrolled MIMO aeroelastic system \\
\hline$\tilde{E}_{f}, \tilde{A}_{f}, \tilde{B}_{f}, \tilde{C}_{f}$ & () & $\begin{array}{l}\text { reduced order state space representation of the uncontrolled MIMO aeroelastic } \\
\text { system }\end{array}$ \\
\hline$F_{s e_{i}}$ & $(N / m)$ & aerodynamic forces acting on a bridge finite element \\
\hline$f$ & $(m)$ & main cable sag \\
\hline$G$ & $\left(N / m^{2}\right)$ & shear modulus of elasticity \\
\hline$G(s)$ & () & MIMO aeroelastic system transfer function \\
\hline$G_{k}(s)$ & () & modal equivalent of MIMO aeroelastic system transfer function \\
\hline$G_{\Delta}(s)$ & () & perturbed system transfer function \\
\hline$H$ & $(N)$ & horizontal cable tension (both cables) \\
\hline$h$ & $(m)$ & vertical (heave) displacement of the deck \\
\hline$h_{e, \min }$ & $(m)$ & length of shortest hanger length \\
\hline$h_{e}+y_{e}$ & $(m)$ & tower height measured from deck \\
\hline$I_{y}$ & $\left(m^{4}\right)$ & second moment of inertia about horizontal axis \\
\hline$I_{z}$ & $\left(m^{4}\right)$ & second moment of inertia about vertical axis \\
\hline$I_{a}$ & $\left(m^{4}\right)$ & torsional moment of inertia \\
\hline$I_{\beta}, I_{\gamma}$ & $\left(m^{4}\right)$ & second moment of inertias of leading and trailing flaps about their hinges \\
\hline$I_{m}$ & $\left(\mathrm{kgm}^{2} / \mathrm{m}\right)$ & mass moment of inertia \\
\hline$k$ & () & non-dimensional reduced frequency \\
\hline$K$ & & MIMO controller matrix \\
\hline$K_{h}, K_{\alpha}$ & $(k N m / m)$ & vertical and torsional bridge mode stiffnesses per unit length \\
\hline$K_{\beta}, K_{\gamma}$ & $(k N m / m)$ & leading and trailing flap retention component stiffnesses per unit length \\
\hline$K_{l}(s), K_{t}(s)$ & & leading and trailing flap controllers excluding the flap retention components \\
\hline$L$ & $(m)$ & element length \\
\hline$l_{h}$ & $(m)$ & average hanger length or each element \\
\hline$L(\cdot)$ & $(N / m)$ & aerodynamic lift force on the deck \\
\hline$l_{d}, t_{d}$ & & parameters determining position of flap pivot points in [5] \\
\hline$m_{g}$ & $(\mathrm{~kg} / \mathrm{m})$ & girder mass per unit length \\
\hline$m_{c}$ & $(\mathrm{~kg} / \mathrm{m})$ & mass of main cables (both cables) per unit length \\
\hline$m_{e}$ & $(\mathrm{~kg} / \mathrm{m})$ & Bridge section mass per unit length \\
\hline$m_{\beta}, m_{\gamma}$ & $(\mathrm{kg} / \mathrm{m})$ & mass of leading and trailing flaps per unit length \\
\hline
\end{tabular}




\begin{tabular}{|c|c|c|}
\hline$M, K, C$ & () & global bridge structural mass, stiffness and damping matrices \\
\hline$M_{a}, K_{a}, C_{a}$ & () & global non-circulatory aerodynamic mass, stiffness and damping matrices \\
\hline$M_{n c, i}, K_{n c, i}, C_{n c, i}$ & & element non-circulatory aerodynamic mass, stiffness and damping matrices \\
\hline$M(\cdot)$ & $(N m / m)$ & aerodynamic moment force on the deck \\
\hline$M^{\beta_{l}}(\cdot), M^{\beta_{t}}(\cdot)$ & $(\mathrm{Nm} / \mathrm{m})$ & Aerodynamic moments on the leading and trailing flaps respectively \\
\hline$M_{c}^{\beta_{l}}(\cdot), M_{c}^{\beta_{t}}(\cdot)$ & $(N m / m)$ & feedback torques for leading and trailing flaps \\
\hline$M, v$ & () & moment velocity pair for a one-port system \\
\hline$\tilde{M}, \tilde{N}$ & () & normalized left coprime co-factors of $G(s)$ \\
\hline$N$ & () & number of elements \\
\hline$P_{N C}(s)$ & () & $\begin{array}{l}\text { system state space representation including system dynamics and non- } \\
\text { circulatory aerodynamic forces }\end{array}$ \\
\hline$q$ & () & displacement vector for each element \\
\hline$Q$ & () & displacement vector for bridge structure \\
\hline$Q_{v}$ & () & velocity vector for bridge structure \\
\hline$R_{j}$ & () & residue matrix corresponding to the eigentriplet $\left(\lambda_{j}, \nu_{j}, w_{j}\right)$ \\
\hline$R_{\infty}(s)$ & () & contribution of the infinity poles at the MIMO transfer function \\
\hline$r_{b}$ & $(m)$ & distance from deck's rotation centre to leading flap pivot point \\
\hline$r_{\text {gam }}$ & $(m)$ & distance from deck's rotation centre to trailing flap pivot point \\
\hline$S_{\alpha}$ & $\left(m^{3}\right)$ & first order moment of inertia of the deck with flap surfaces \\
\hline$S_{\beta}, S_{\gamma}$ & $\left(m^{3}\right)$ & first order moment of inertias of leading and trailing flaps about their hinges \\
\hline$r$ & () & Laplace variable \\
\hline$T_{i j}(\cdot)^{\prime} s$ & () & functions defined in [5] \\
\hline$U$ & $(m / s)$ & nd velocity \\
\hline$u(s)$ & () & output from the $C(s)$ transfer function \\
\hline$W_{s e}$ & $(\mathrm{~kg} / \mathrm{m})$ & weight of the suspended structure per unit length \\
\hline$W_{c e}$ & $(\mathrm{~kg} / \mathrm{m})$ & weight of the main cable per unit length \\
\hline$x$ & () & structural state vector \\
\hline$x_{f}, \tilde{x}_{f}$ & () & state vector of the original and reduced uncontrolled aeroelastic systems \\
\hline$X, Y$ & () & $\begin{array}{l}\text { matrices containing the left and right eigenvectors } w_{i} \text { and } v_{i} \text { of the corresponding } \\
\text { dominant poles as columns }\end{array}$ \\
\hline$\hat{x}$ & () & structural and aerodynamic state vector \\
\hline$y(s)$ & () & input to the $C(s)$ transfer function \\
\hline$Y_{g l}(s), Y_{g t}(s)$ & () & $\begin{array}{l}\text { passive networks for the leading and trailing flaps including retention compo- } \\
\text { nents }\end{array}$ \\
\hline$z$ & () & output vector of the aeroelastic state space representation \\
\hline$\alpha$ & $(\mathrm{rad})$ & torsional (pitch) rotation of the deck \\
\hline$\beta_{l}, \beta_{t}$ & $(\mathrm{rad})$ & leading and trailing flap angles \\
\hline$\Delta_{M}, \Delta_{N}$ & () & $\begin{array}{l}\text { additive model errors associated with the coprime co-factors of the transfer func- } \\
\text { tion }\end{array}$ \\
\hline$\varepsilon_{\max }$ & () & largest achievable stability margin \\
\hline$\left(\lambda_{i}, v_{i}, w_{i}\right)$ & () & an eigentriplet of the MIMO uncontrolled aeroelastic system \\
\hline$\mu=(5 / 6) A$ & & effective shear area \\
\hline$\rho$ & $\left(\mathrm{kg} / \mathrm{m}^{3}\right)$ & air density \\
\hline & $\left(\mathrm{kg} / \mathrm{m}^{3}\right)$ & flap density \\
\hline$\Phi=\frac{12 E I_{y}}{G u L^{2}}$ & () & shear coefficient \\
\hline & () & circulatory aerodynamic forces for an element \\
\hline & & circulatory aerodynamic forces in FE framework \\
\hline$\omega_{h}, \omega_{\alpha}$ & $(\mathrm{rad} / \mathrm{s})$ & vertical and torsional resonant frequencies for bridge structure \\
\hline$\omega_{\beta}, \omega_{\gamma}$ & $(\mathrm{rad} / \mathrm{s})$ & leading and trailing flaps resonant frequencies \\
\hline & $(\%)$ & vertical and torsion bridge mode damping ratios \\
\hline
\end{tabular}


\begin{tabular}{|l|l|l}
$\zeta_{\beta}, \zeta_{\gamma}$ & $(\%)$ & leading and trailing flap damping ratios
\end{tabular}

Table 1: List of symbols

The investigation undertaken in this paper extends previous work on aeroelastic control using controllable winglets $[6,7]$ by considering the full bridge structure. The work revisits the finite element (FE) structural modelling approach proposed by Abdel Ghaffar [8,9,10], which results in a low-order model that achieves good agreement with experimentally-derived measurement data $[11,12]$. The FE model is extended to include the deck-flap control system. The use of a full 3D bridge model facilitates the modelling of finite-length controllable surfaces and accounts fully for the observed multimodal interactions.

FE-based aeroelastic analysis of long span bridges, using a frequency domain formulation of the unsteady aerodynamic forces, has been pursued extensively in the past $[13,14,15]$. In that respect, the determination of aeroelastic boundaries is based on an iterative procedure for both the wind speeds and the frequencies of the oscillatory forces. Related algorithms inherited from the aeronautical industry include the k-method and the (p-k)-method [16]. Several authors $[6,17,18]$ have made use of a rational function approximation procedure for modelling unsteady aerodynamic forces which allow the equations of motion to be cast in a linear time-invariant state-space form, making iterative stability analyses redundant. In this work we pose the aerodynamic stability problem in the state-space by employing separate high-fidelity rational approximations of the Theodorsen circulation function for each bridge element. This procedure allows the aerodynamic state dimension to be halved [19]. The aerodynamic loading distribution follows the strip theory assumption, whose implications for aerodynamic load prediction have been recently discussed in [20], principally for buffet by incident turbulence. This was shown to hold accurately for deck platform aspect ratios, wavelengths of structural modes, and turbulence length scales typical of such bridges.

It is apparent from the experience gained on projects such as the Akashi Kaikyo Bridge and the Great Belt East Bridge that classic aerodynamic design processes reach their limit at spans lengths approaching 2000m [21]. Attempts to extend this limit by improved aerodynamic performance include modification to the deck shape and the use of static aerodynamic appendages. Examples include the triple-girder deck for the proposed Messina Strait Bridge, resulting in a flutter wind speed of $80 \mathrm{~m} / \mathrm{s}$ on a $3300 \mathrm{~m}$ span [22]. Larsen has shown that improved aerodynamic performance can be achieved by deck slotting [23]. Other examples include vertical and horizontal stabilizers [24] and fixed winglets. These methods have the advantage of providing a passive solution to the problem. However, as span lengths increase, the economic efficiency of these methods decline due to a necessary increase in the girder separation. There are also construction and maintenance issues to be addressed [25]. In this paper we focus on the use of passively-controlled flaps that generate stabilizing aerodynamic forces. As shown in Fig. 1 these flaps can be either adjacent to the deck, or at some distance above or below it.

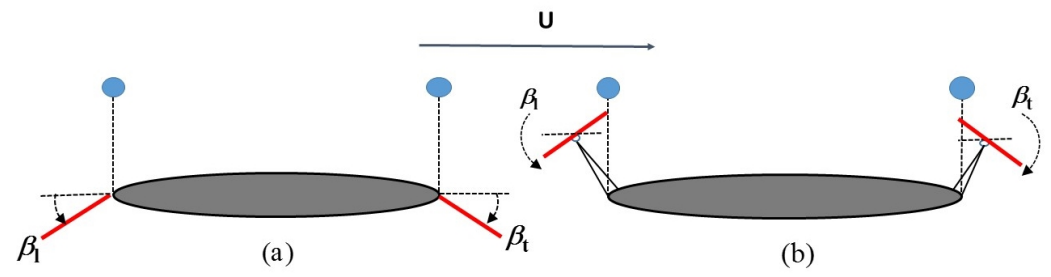

Figure 1: Suspension bridge cross section with controllable leading- and trailing-edge flaps. Flaps are either adjacent to the bridge deck (a), or separated from it (b). The leading-edge flap angle is denoted as $\beta_{l}$ and the trailing-edge flap angle as $\beta_{t}$.

The configuration shown in Fig. 1 (a) is the one considered here. In the second case, given that the deck and flaps are assumed aerodynamically independent, a large separation is required ( $>1$ deck width for the trailing-edge flap) which undermines the applicability of this configuration, as was explained in [6]. Flap-based flutter suppression systems have been examined both analytically and experimentally during the past twenty years without thus far have been implemented. The control of bridge flutter using actively controlled flaps located beneath the deck was first proposed in [26]. More recently Li [25] used a pair of rotatable winglets at a distance from the deck. Optimal control strategies and pole placement algorithms provide viable solutions, but can lead to very poor robustness properties. 
In the aircraft industry flutter suppression has been under development with emphasis on using actively controlled trailing edge flaps [27, 28]. Bakis et al. [19] developed an aeroelastic control framework for investigating flutter effectiveness on a full bridge model, by implementing an $\mathcal{H}_{\infty}$ control strategy, which is shown to be successful in quantifying uncertainties.

Passive flap control mechanisms have the advantage of not requiring an external power source, because these systems use a mechanical coupling network to transform deck movements into flap rotations. Omenzetter et al. [29] proposed a mechanical system in which the flap is linked by wires and pre-stressed springs to an auxiliary transverse beam supported by the main cables. A sectional analysis suggested that an increase in the critical wind speed requires large flaps and a very stiff transverse beam. A subsequent 3D analysis [17] showed that the coupling between the flap rotation and the horizontal motion of the deck, and the main cables limits achievable improvements in the critical flutter speed. Wilde et al. [30] proposed an alternative mechanism in which the motion of the flaps is kinematically constrained by a pendulum-based mechanism within the deck structure. Analytical and experimental analyses showed that for a sectional model an increase up to 57\% can be obtained. Pure gain controllers forego the advantages that might accrue from phase compensation, whereas fixed-phase controllers are not physically realizable. Phase compensating schemes are introduced in [6,31], but the proposed design is only realizable if it can be anchored to an inertial reference frame. Kwon [32] proposed a design based on tuned mass-dampers connected through a transmission system to aerodynamic surfaces, which oscillate through slits in the bottom flange of the deck. Starossek [33] presented preliminary results of a similar passive system in which the damper is connected to leading- and trailing-edge flaps.

The feasibility of passive control schemes on the erection stage of suspension bridges for flutter and buffeting has also been investigated by the authors in $[34,35]$ but further investigation was deemed necessary. In the early stages of deck construction, suspension bridges are particularly vulnerable to flutter instabilities [36]. the greatly reduced stable wind speed range during partial erection is a matter of concern to bridge designers and while various solutions or precautionary measures are usually considered [37] the use of a deployable (i.e. independent of the actual bridge structure) flap system is another such measure which may well be more convenient and effective to provide full security during this phase of construction. In order to study these effects in detail, the aeroelastic performance of the Humber Bridge is studied at various stages of completion and the contribution of controllable surfaces is investigated in that respect.

In Bakis et al. [7] two passive mechanical feedback mechanisms were proposed by the authors, which overcome limiting shortcomings of previous structures. The first, makes use of trailing and leading-edge flaps adjacent to the deck, passively controlled by a combination of springs, dampers and inerters at the hinge connection. The second, combines the flaps' aerodynamic contribution with a driving force derived from a tuned mass inside the deck section. Both solutions exploit favourable aerodynamic configurations to increase aeroelastic stability boundaries. In this paper we elaborate further on the first strategy, which is practically simple to implement. A full-mode aeroelastic FE model is employed to examine its performance during the erection stage and completed deck stage of the Humber Bridge. It is shown that the proposed passive feedback system significantly increases the flutter and torsional divergence boundaries during early process of construction as well as in the final completion stage, and simultaneously achieves good stability resistance to structural parametric uncertainty.

\section{Structural Model}

The bridge finite element (FE) model uses the framework proposed by Abdel Ghaffar [8, 9, 10]. It is shown that this methodology, while producing low-order models, also provides good agreement with experimentally derived modal properties; a model of approximately 120 structural degrees of freedom is used. In this section we present results based on the complete Humber Bridge as well as during its partially erection stages.

\subsection{Modelling Methodology}

The model developed here assumes that there is no coupling between vertical, lateral and torsional motions, an assumption that is supported by the measured modal characteristics of long-span suspension bridges. It is further assumed that in the purely vertical modes, all points in a given cross section move in phase and by the same amount. In torsion, the bridge sections are assumed to rotate about their central points. For lateral motions, each cross section 


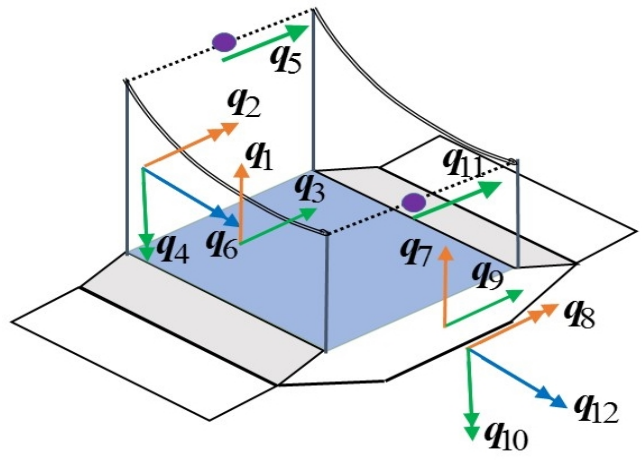

(a)

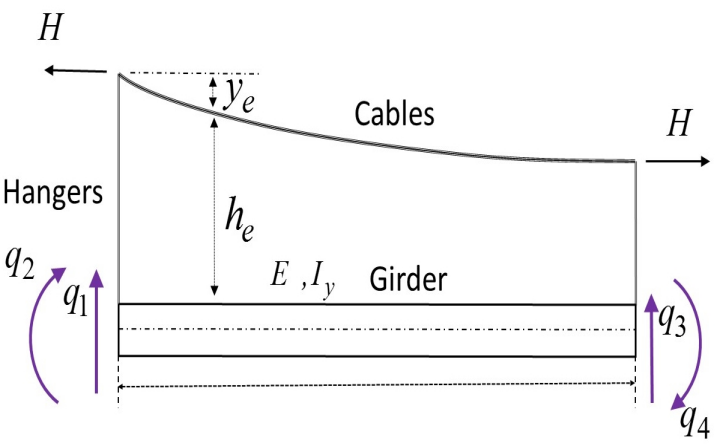

(b)

Figure 2: (a) FE Degrees of freedom used. Vertical freedoms $q_{1}, q_{2}, q_{7}, q_{8}$ are shown in orange, lateral freedoms $q_{3}, q_{4}, q_{5}, q_{9}, q_{10}, q_{11}$ are shown in green, torsional freedoms $q_{6}, q_{12}$ are shown in blue. (b) Sectional view of nodal freedoms for the vertical case.

is assumed to swing 'like a pendulum' in its own vertical plane, resulting in an incidental upward movement of the cables and the suspended structure. The hangers are assumed inextensible. With these assumptions in place, a single finite element can be formulated that represents a section of the deck and cables. Fig.2 presents the geometry and nodal degrees of freedom of a typical element, showing (a) an isometric view defining the element's 12 DOFs (6 per node) and (b) an elevation showing the two DOFs per node associated with vertical vibration. Element stiffness and mass matrices are derived from the potential and kinetic energy of the cables and suspended structure, using an appropriate shape function.

\subsection{Humber Bridge Description and Modal Analysis Results}

Table 2: Structural properties of the FE model of the Humber Bridge.

\begin{tabular}{lll}
\hline Element & Property & Value \\
\hline \multirow{4}{*}{ girder } & Young's modulus of elasticity & $E=210 \times 10^{9} \mathrm{~N} / \mathrm{m}^{2}$ \\
& shear modulus of elasticity & $G=80.8 \times 10^{9} \mathrm{~N} / \mathrm{m}^{2}$ \\
& element length & $L=100 \mathrm{~m}$ \\
& half chord width of the deck & $b=14.25 \mathrm{~m}$ \\
& girder mass & $m_{g}=13215 \mathrm{~kg} / \mathrm{m}$ \\
& moment of inertia about horizontal axis & $I_{y}=2.09 \mathrm{~m}^{4}$ \\
& moment of inertia about vertical axis & $I_{z}=41.24 \mathrm{~m}^{4}$ \\
& torsional moment of inertia & $I_{a}=4.49 \mathrm{~m}^{4}$ \\
& mass moment of inertia (including cables) & $I_{m}=1.05 \times 10^{6} \mathrm{kgm} / \mathrm{m}$ \\
\hline \multirow{4}{*}{ cables } & Young's modulus of elasticity & $E_{c}=155.5 \times 10^{9} \mathrm{~N} / \mathrm{m}^{2}$ \\
& cross sectional area & $A_{c}=0.362 \mathrm{~m}^{2}$ \\
& half distance between main cables & $b_{c}=10.98$ \\
& diameter & $d_{c}=0.68 \mathrm{~m}$ \\
& mass of the main cables (both cables) & $m_{c}=3000 \mathrm{~kg} / \mathrm{m}$ \\
& horizontal cable tension (both cables) & $H=2 \times 3.08 \times 10^{8} \mathrm{~N}$ \\
& main cable sag & $f=115.5 \mathrm{~m}$ \\
& length of shortest hanger cable & $h_{e, \text { min }}=17.5 \mathrm{~m}$ \\
\hline
\end{tabular}

The Humber Bridge is currently the seventh longest single-span suspension bridge in the world. Similarly to its contemporaries Severn and Bosporus Bridges, it has a streamlined flat box girder deck. The towers are made from concrete heavily reinforced hollow box sections, while the side spans have unequal lengths, Fig. 3 . The suspended span between the towers is $1410 \mathrm{~m}$ long and the main girder has a width of $22 \mathrm{~m}$, excluding the footways, and a depth of 4.5 $\mathrm{m}$, giving a span:depth ratio of just over 300. The deck girder is built from $18.1 \mathrm{~m}$ long prefabricated segments, fitted with four equally spaced bulkheads to improve the torsional stiffness. Five panels each $3.25 \mathrm{~m}$ wide are cantilevered 
outward along each side of the box girder to carry the footways. The structural parameters implemented in the FE model are given in Table.2.

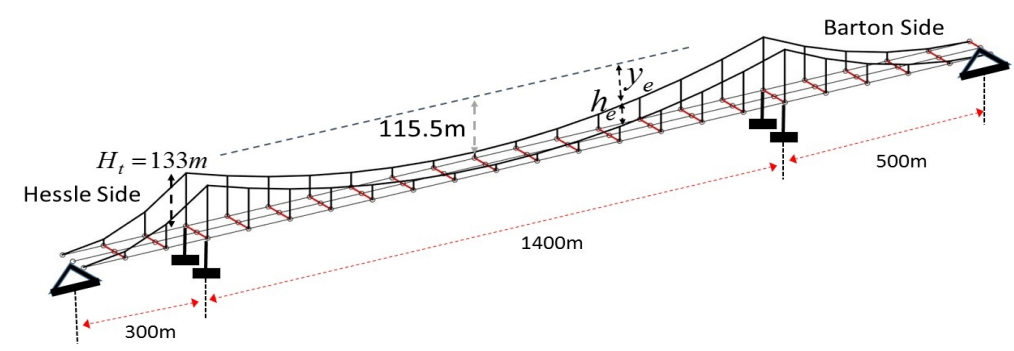

Figure 3: Basic dimensions of the Humber Bridge FE model.

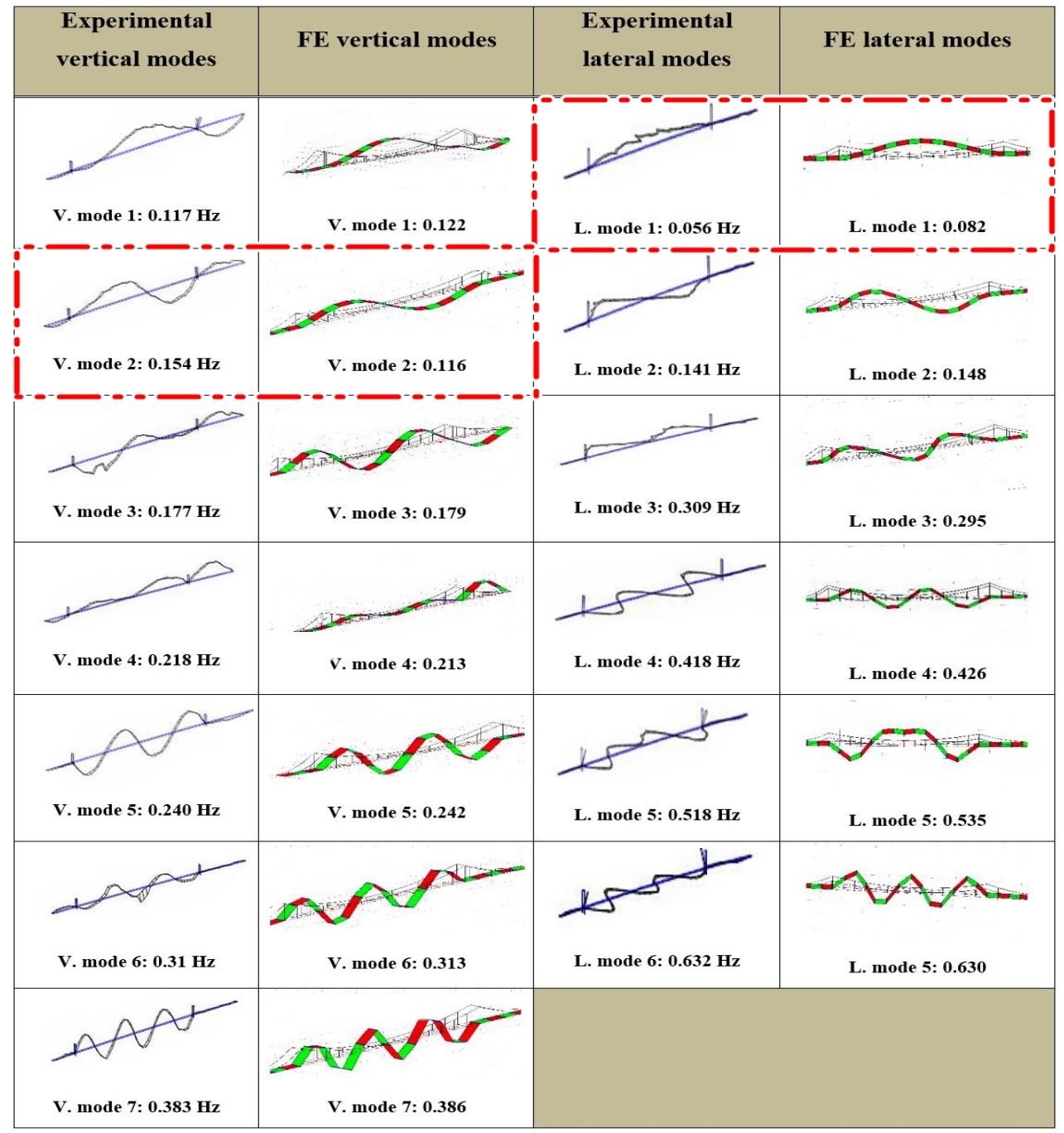

Figure 4: Comparison of experimentally identified, [12], vertical and lateral modal characteristics to FE results. Red boxes mark the modes for which there is discrepancy between experimental and FE modelling results. 
The natural frequencies of the vertical, lateral and torsional modes obtained from the FE model are shown in Figs. 4 and 5, which were refined using the field monitoring results of Brownjohn et al. [11, 12].

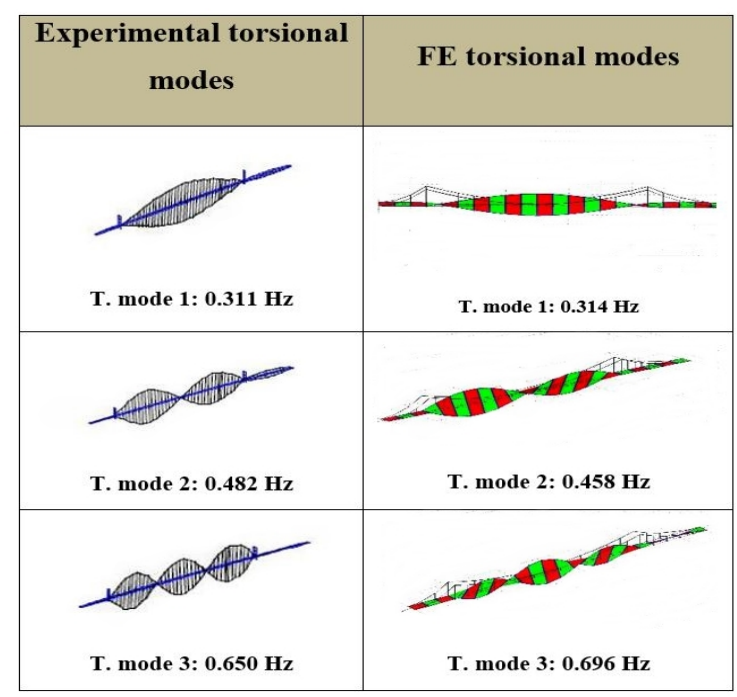

Figure 5: Comparison of experimentally identified, [12], torsional modal characteristics to FE results.

From this comparison it can be noted:

1. The FE procedure results in a very good predictions of the structure's vertical and torsional modes.

2. The observed difference in the first vertical antisymmetric mode is due to this mode's coupling with the deck's longitudinal motion. Is has been estimated that the mode's natural frequency ranges from 0.105 to $0.145 \mathrm{~Hz}$ depending if the axial motion is free or constrained at both ends of the deck respectively [38]. In our model the axial motion is neglected.

3. The first lateral mode is less accurately reproduced by the structural FE framework. Possible reasons for this include: a) A more pronounced tower participation in the lateral deck modes. In the lateral direction, tower participation is expected to be more significant, because the deck lateral response is an order of a magnitude weaker than in the vertical plane [12] b) Significant low-frequency traffic-induced noise in the frequency range of that mode. c) The mathematical difficulty in expressing in-phase and out-of-phase motion of the deck and the cables in the lateral model, given the adopted assumptions [10].

4. Prediction of aeroelastic limits is much less dependent on sway motion and thus it is concluded that the FE model accurately captures the structure's dynamics relevant to aerodynamic instabilities.

\subsection{Modelling of the Erection Stage}

In this section we use the FE model to estimate the Humber bridge's modal characteristics during the erection stage. The erection-stage bridge dynamics are an issue of concern, because the partially erected deck is significantly more vulnerable to flutter instabilities. As shown in $[36,39]$, the ratio of the fundamental torsional-to-vertical frequency is an effective indicator of the flutter stability boundary. The key structural performance characteristics of the bridge during erection are these:

1. Reduced torsional stiffnesses in the early stages of construction are responsible for degraded aerodynamic stability limits. This is because deck stiffness contributes significantly to the torsional rigidity of the structure;

2. The bridge's vertical stiffness is less sensitive to construction influences, because it is dominated by the main cables;

3. The added inertia with increasing number of deck segments affects mostly the vertical modes because of the associated lower rotational inertia compared to that of the cables. The cable mass, at a larger distance from the centre line of the bridge, produces in fact a higher rotational inertia for the same amount of translational mass; 


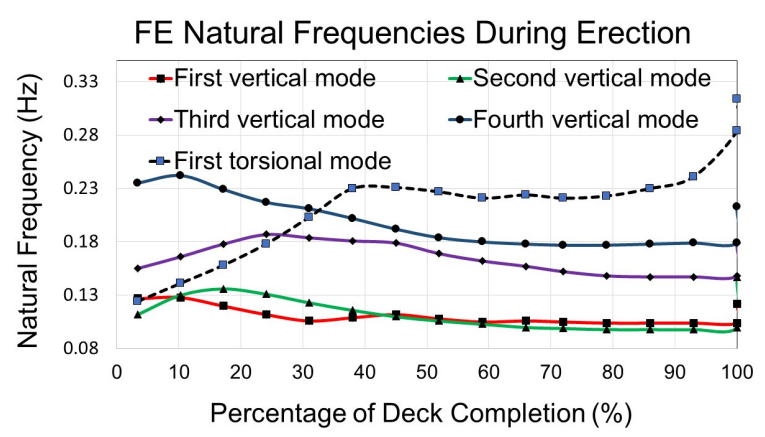

(a)

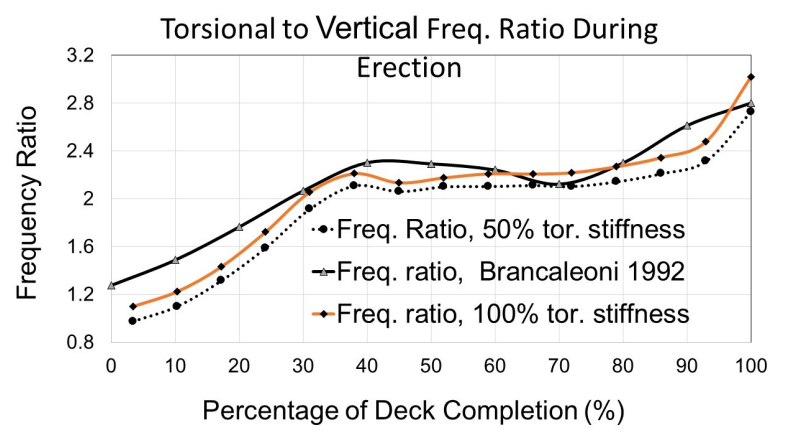

(b)

Figure 6: (a) Evolution of natural frequencies for vertical and torsional modes during deck erection. (b) Frequency ratio (torsional to vertical mode) dependence on deck completion and comparison with data taken from [36].

4. Temporary connections between the deck segments during erection result in increased deck stiffness contributions to the torsional modes compared to the vertical ones;

5. The influence of the towers on the bridge's modal behaviour is dependent on the bridge type and the erection sequence. Since the tower stiffnesses are much larger than that of the cables, their influence is minimal in the early erection stages, which are the most aerodynamically interesting ones;

6. The critical flutter speed is at its lowest when approximately $10-20 \%$ of the bridge has been suspended. At this stage the deck is long enough to pick up significant aerodynamic excitation force, while torsional stiffness is low and the ratio of the fundamental torsional to vertical frequency is closer to unity.

The same finite element is used for both the full and partially complete bridge model. When modelling the incomplete portions of the bridge during construction, mass and stiffness of the corresponding finite elements are considered negligible. To account for the temporary connections, whose purpose is to avoid locked-in bending stresses, we halve the torsional rigidity of all the construction stages, whereas the flexural stiffness is neglected altogether [36]. During the various stages of completion, the cable's horizontal force and the additional displacement resulting from the added weight must be determined by solving the nonlinear cable equations [40]. Fig. 6 shows the evolution of the vertical and torsional frequencies, and the ratio of the first torsional to vertical frequency at different construction stages. Comparison is made to previous analysis reported in Brancaleoni [36]. The following observations and notes relate to the presented analysis:

1. A symmetric deck construction process was adopted, which follows closely the actual erection sequence;

2. An element size of $50 \mathrm{~m}$ was adopted;

3. The natural frequencies of the vertical modes remain approximately constant during the assembly process;

4. The torsional stiffness increases rapidly during the initial $40 \%$ of construction, and then remains constant during the remaining intermediate stages. The final stiffness increase at completion is due to the final stiffening of the temporary connections;

5. The frequency ratio resulting from this analysis follows a trend similar to that in Brancaleoni [36].

6. When the erect deck section is short, the torsional and vertical modal frequencies are close to each other, and correspond respectively to the in-phase and out-of-phase movements of the cables.

7. Fig. 7 shows the fundamental torsional mode at different stages of construction. At approximately $40 \%$ completion, there is a clear transition in mode shape that explains the flattening of the torsional natural frequency curve.

\subsection{Sectional flap-deck system dynamics}

In this section the dynamic modelling of a sectional representation of the deck-flap system is described. This model typically represents the lowest-frequency bending and torsional modes of the structure. As shown in Fig. 8 (a), the sectional model of the deck-flap system is assumed to have four degrees of freedom. These freedoms include the 


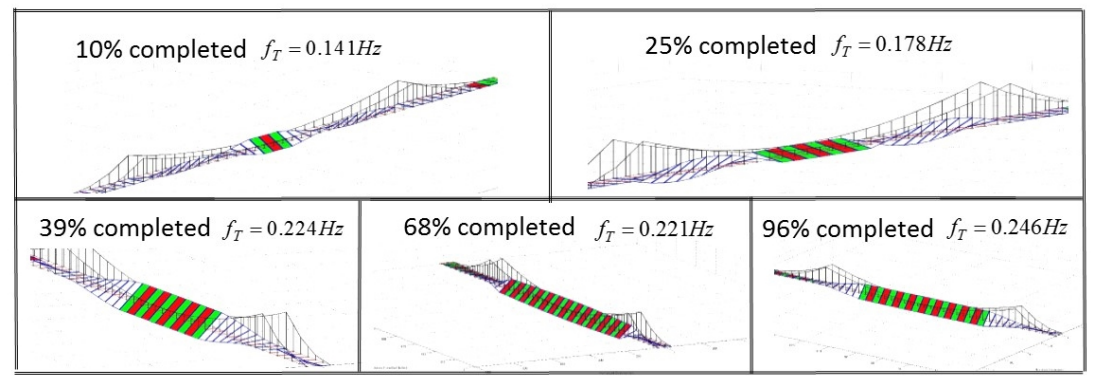

Figure 7: Evolution of the fundamental torsion mode at progressive construction stages. The deck's torsional stiffness is assumed during erection to be half its final value with the flexural stiffness neglected due to the temporary connections.

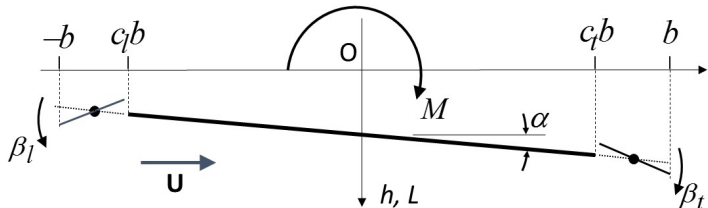

(a)

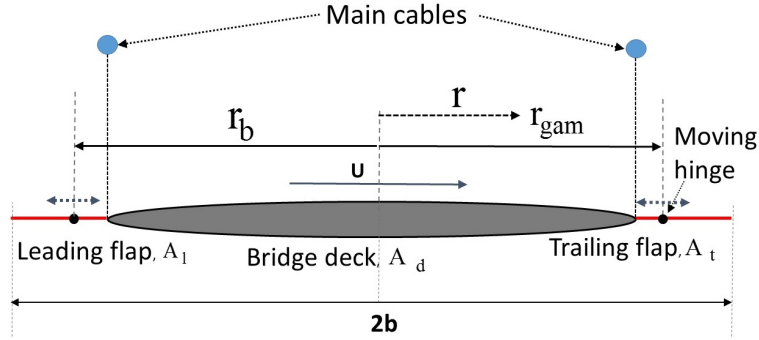

(b)

Figure 8: (a) Kinematic model of the bridge deck. The wind velocity $U$ is assumed positive to the right, the heave $h$ and lift force $L$ are assumed positive downwards, the moment $M$ is positive clockwise, as are the pitch and trailing-edge flap angles $\alpha$ and $\beta_{t}$ respectively. The leading-edge flap angle $\beta_{l}$ is positive anti-clockwise. The deck chord (including the flaps) is $2 b$. The leading-and trailing-edge flap chords are $\left(1+c_{l}\right) b$ and $\left(1-c_{t}\right) b$ respectively; note that $c_{l}$ is a negative quantity. (b) Bridge deck-flap system notation.

deck's pitch angle $\alpha$, the deck's heave $h$ with respect to the elastic centre, and the leading-and trailing-edge flap angles $\beta_{l}$ and $\beta_{t}$.

For the presented system the corresponding equations of motion are:

$$
\text { Deck-lift : } m \ddot{h}+S_{\alpha} \ddot{\alpha}+S_{\beta} \ddot{\beta_{l}}+S_{\gamma} \ddot{\beta_{t}}+C_{h} \dot{h}+K_{h} h=L,
$$

$$
\begin{aligned}
& \text { Deck-moment : } S_{\alpha} \ddot{h}+I_{\alpha} \ddot{\alpha}-\left(I_{\beta}-b c_{l} S_{\beta}\right) \ddot{\beta}_{l}+\left(I_{\gamma}+b c_{t} S_{\gamma}\right) \ddot{\beta}_{t}+C_{\alpha} \dot{\alpha}+K_{\alpha} \alpha=M \\
& \text { Leading-flap moment : } S_{\beta} \ddot{h}-\left(I_{\beta}-b c_{l} S_{\beta}\right) \ddot{\alpha}+I_{\beta} \ddot{\beta}_{l}+C_{\beta} \dot{\beta}_{l}+K_{\beta} \beta_{l}=M^{\beta_{l}}+M_{c}^{\beta_{l}} \\
& \text { Trailing-flap moment : } S_{\gamma} \ddot{h}+\left(I_{\gamma}+b c_{t} S_{\gamma}\right) \ddot{\alpha}+I_{\gamma} \ddot{\beta}_{t}+C_{\gamma} \dot{\beta}_{t}+K_{\gamma} \beta_{t}=M^{\beta_{t}}+M_{c}^{\beta_{t}}
\end{aligned}
$$

where:

$$
S_{\alpha}=\int_{A_{d}+A_{l}+A_{t}} r d m \quad S_{\beta}=-\int_{A_{l}}\left(r-r_{b}\right) d m \text { and } S_{\gamma}=\int_{A_{t}}\left(r-r_{g a m}\right) d m .
$$

$m$ is mass per unit length and $I_{a}$ is the second moment of inertia of the deck-flap system about the deck elastic centre, $I_{\beta}$ and $I_{\gamma}$ are the second order moments of inertia of the leading and trailing flaps about their hinges, respectively. $A_{d}, A_{l}, A_{t}$ are the cross section areas of the deck, leading and trailing flaps respectively. $r_{b}$ denotes the distance from the deck's rotation centre to the leading flap's pivot point and similarly $r_{\text {gam }}$ is the distance from the deck's rotation centre to the trailing flap's pivot point. The subscripts $\alpha, \beta, \gamma$ designate the whole deck, and the leading- and trailingedge flaps respectively.

$$
I_{\alpha}=\int_{A_{d}+A_{l}+A_{t}} r^{2} d m \quad I_{\beta}=\int_{A_{l}}\left(r-r_{b}\right)^{2} d m \text { and } I_{\gamma}=\int_{A_{t}}\left(r-r_{g a m}\right)^{2} d m
$$


$K$ is stiffness and $\zeta$ the damping ratio per unit length, and the subscripts $h$ and $\alpha$ designate the heave and torsional motions respectively. The flap hinges are at $c_{l} \mathrm{~b}$ and $c_{t} \mathrm{~b}$, where $c_{l}<0$ and $c_{t}>0$. For modelling the bridge-flap structure as a sectional model the heave and torsional resonant frequencies $\omega_{h}$ and $\omega_{\alpha}$ are assumed known for the investigated bridge. The equivalent spring stiffnesses are computed using $K_{h}=m \omega_{h}^{2}$ and $K_{a}=I_{\alpha} \omega_{\alpha}^{2}$. The flap frequencies $\omega_{\beta}$ and $\omega_{\gamma}$ are similarly computed using $K_{\beta}=I_{\beta} \omega_{\beta}^{2}$ and $K_{\gamma}=I_{\gamma} \omega_{\gamma}^{2}$. Similarly, the damping terms are: $C_{h}=2 \zeta_{h} \omega_{h} m$, $C_{a}=2 \zeta_{\alpha} \omega_{a} I_{a}, C_{\beta}=2 \zeta_{\beta} \omega_{\beta} I_{\beta}$ and $C_{\gamma}=2 \zeta_{\gamma} \omega_{\gamma} I_{\gamma}$. The aerodynamic lift and moment on the bridge deck are given by $L$ and $M$ respectively. The aerodynamic moments $M^{\beta_{l}}$ and $M^{\beta_{t}}$ act, respectively, around the leading- and trailing-edge flap hinges. The flap control torques are given by $M_{c}^{\beta_{l}}$ and $M_{c}^{\beta_{t}}$. The mass per unit span of the flaps is given by

$$
m_{\beta}=b\left(1+c_{l}\right) \rho_{f} d_{f} \quad m_{\gamma}=b\left(1-c_{t}\right) \rho_{f} d_{f},
$$

where $\rho_{f}$ and $d_{f}$ are the density and thickness of the flaps respectively. The aeroelastic framework for the sectional model is in detail presented in [7] and is based on a transformation of the Theodorsen-Garrick aerodynamic expressions [41] for deriving the aerodynamic forces on the deck section and flaps. This approach is extended to the FE bridge model by incorporating the flap dynamics into the bridge dynamics. The structural matrices including flap terms are given in 9.1 .

\section{Aerodynamic Model}

Assuming thin aerofoil theory, the aerodynamic lift $(L)$ and aerodynamic moments $M, M^{\beta_{l}}$ and $M^{\beta_{t}}$ are as given by Theodorsen and Garrick [41]. The transformation introduced in $[6,19]$ is used to derive the lift and moment acting on the deck and flaps, which can be expressed in the following matrix form for element $i$ :

$$
F_{s e_{i}}=M_{n c_{i}} \ddot{q}+C_{n c_{i}} \dot{q}+K_{n c_{i}} q+\xi_{C}
$$

Where, $q$ is the position vector containing the structural freedoms for an element. $\xi_{C}$ represents the circulatory aerodynamic terms for the element. The equations of motion of the FE model, combined with the aerodynamic forces given in Eq. (8), are expressed in state space form as:

$$
\left[\begin{array}{cc}
0 & M-M_{a} \\
I & 0
\end{array}\right]\left[\begin{array}{c}
\dot{Q} \\
\dot{Q}_{v}
\end{array}\right]=\left[\begin{array}{cc}
-K+K_{a} & -C+C_{a} \\
0 & I
\end{array}\right]\left[\begin{array}{c}
Q \\
Q_{v}
\end{array}\right]+\Xi_{C},
$$

$Q$ is a vector containing the displacement degrees of freedom of the bridge structure. $Q_{v}$ are the related velocities to the structural degrees of freedom and $\Xi_{C}$ represent the circulatory terms in the FE multi-modal framework. Eq.(9) can be written as:

$$
E_{c} \dot{x}=A_{c} x+\Xi_{C}
$$

where $x=\left[Q Q_{v}\right]^{T}$ is the state vector, and

$$
E_{c}=\left[\begin{array}{cc}
0 & M-M_{a} \\
I & 0
\end{array}\right] \quad A_{c}=\left[\begin{array}{cc}
-K+K_{a} & -C+C_{a} \\
0 & I
\end{array}\right]
$$

the quantities $M_{n c_{i}}, C_{n c_{i}}$ and $K_{n c_{i}}$ describe the non-circulatory part of the aerodynamic forces. As shown in Fig. 9, the modelling procedure adopted here concentrates the aerodynamic forces on the element nodes. The full non-circulatory matrices are: $M_{a}=\sum_{i=1}^{N} M_{n c, i}, C_{a}=\sum_{i=1}^{N} C_{n c, i}$ and $K_{a}=\sum_{i=1}^{N} K_{n c, i}$, where $M, C$ and $K$ are the global structural matrices.

The $\Xi_{C}$ equations are dependent on the irrational Theodorsen function $C(k)$, which can be approximated by a rational function $[19,7,6]$. In this framework $C(s)$ is a transfer function that receives structural responses $y(s)=Q_{T}$ as inputs, and generates an output $\tilde{y}(s)=u(s)$, which translates into lift force and moment by the matrix $B$, Fig. 10 (a). A state-space realization $\tilde{A}, \tilde{B}, \tilde{C}, \tilde{D}$ of $C(s)$ can be derived using standard techniques; a fourth order approximation is used here. The modelling operation is repeated for every element as shown in Fig. 10 (b). 

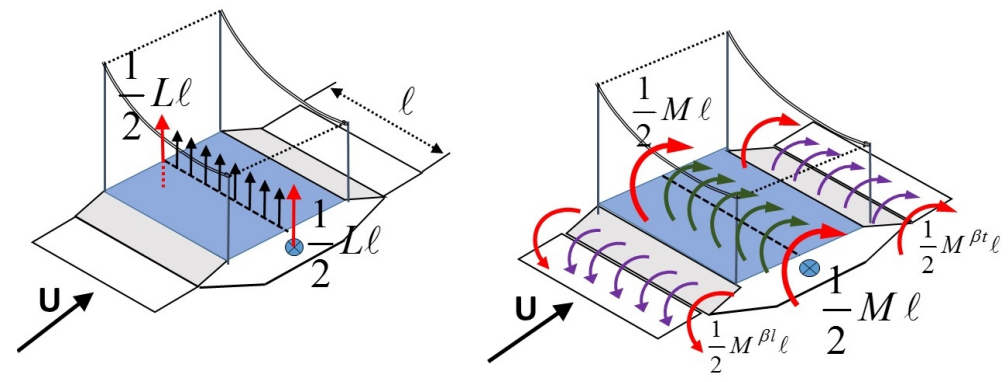

Figure 9: Relating the aerodynamic forces to the element nodes.

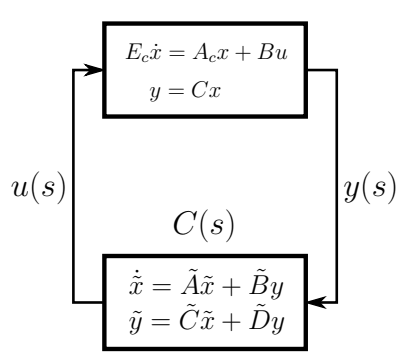

(a)

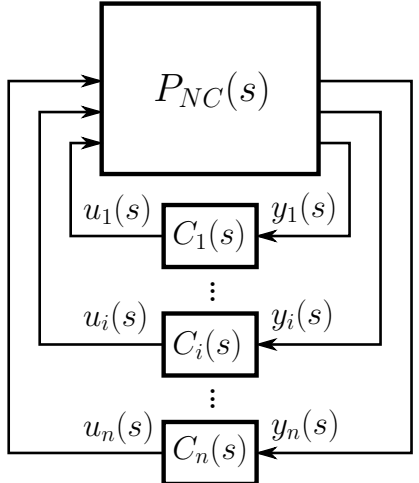

(b)

Figure 10: (a) Block diagram of the sectional open-loop aerodynamic system. (b) Block diagram of the open-loop FE model. $P_{N C}(s)$ is the aeroelastic model without the circulatory terms, and $C_{i}(s)$ are Theodorsen function approximations for each deck element.

$$
Q_{T}=\dot{h}+U a+\frac{1}{2} b \dot{a}+\left(\frac{1}{\pi} T_{10}\left(c_{l}\right) U-U\right) \beta+\left(\frac{1}{2 \pi} T_{11}\left(c_{l}\right) b+c_{l} b-\frac{1}{2} b\right) \dot{\beta}+\frac{1}{\pi} T_{10}\left(c_{t}\right) U \gamma+\frac{1}{2 \pi} T_{11}\left(c_{t}\right) b \dot{\gamma}
$$

and

$$
B=\left[\begin{array}{llllllll}
-2 \pi \rho U b & \pi \rho U b^{2} & -\left(\pi+T_{12}\left(c_{l}\right)+2 \pi c_{l}\right) \rho U b^{2} & -T_{12}\left(c_{t}\right) \rho U b^{2} & 0 & 0 & 0 & 0
\end{array}\right]^{T} .
$$

The Theodorsen function $C(k)$ and the $T_{i j}(\cdot)$ 's are derived in [41], where $k=\omega b / U$ is the reduced frequency.

Standard reduction techniques can be used to combine the various elements in Fig. 10 into the generalized eigenvalue form:

$$
E_{g} \dot{\hat{x}}=A_{g} \hat{x}
$$

where

$$
E_{g}=\left[\begin{array}{cc}
E_{c} & 0 \\
0 & I
\end{array}\right] \quad A_{g}=\left[\begin{array}{cc}
A_{c}+B_{g} \widetilde{D}_{g} C_{g} & B_{g} \widetilde{C}_{g} \\
\widetilde{B}_{g} C_{g} & \widetilde{A}_{g}
\end{array}\right]
$$

The various partitions are given by $\tilde{A}_{g}=\operatorname{diag}(\tilde{A}), \tilde{B}_{g}=\operatorname{diag}(\tilde{B}), \tilde{C}_{g}=\operatorname{diag}(\tilde{C}), \tilde{D}_{g}=\operatorname{diag}(\tilde{D})$. The state-vector $\hat{x}$ in (14) includes the structural states, their velocities and the aerodynamic states related to the Theodorsen function approximations.

The stability of the open-loop system can be analysed using the root locus diagram in Fig. 11. This figure shows the real and imaginary parts of the eigenvalues of the general eigenvalue problem given in Eq.(14). This equation is 
dependent on the wind speed which is the varied parameter. In the uncontrolled case as presented in Fig. 11, the flaps are considered rigidly attached to the deck. The wind speed at which the real part of an eigenvalue becomes positive signifies the onset of unstable motion $[42,19]$.

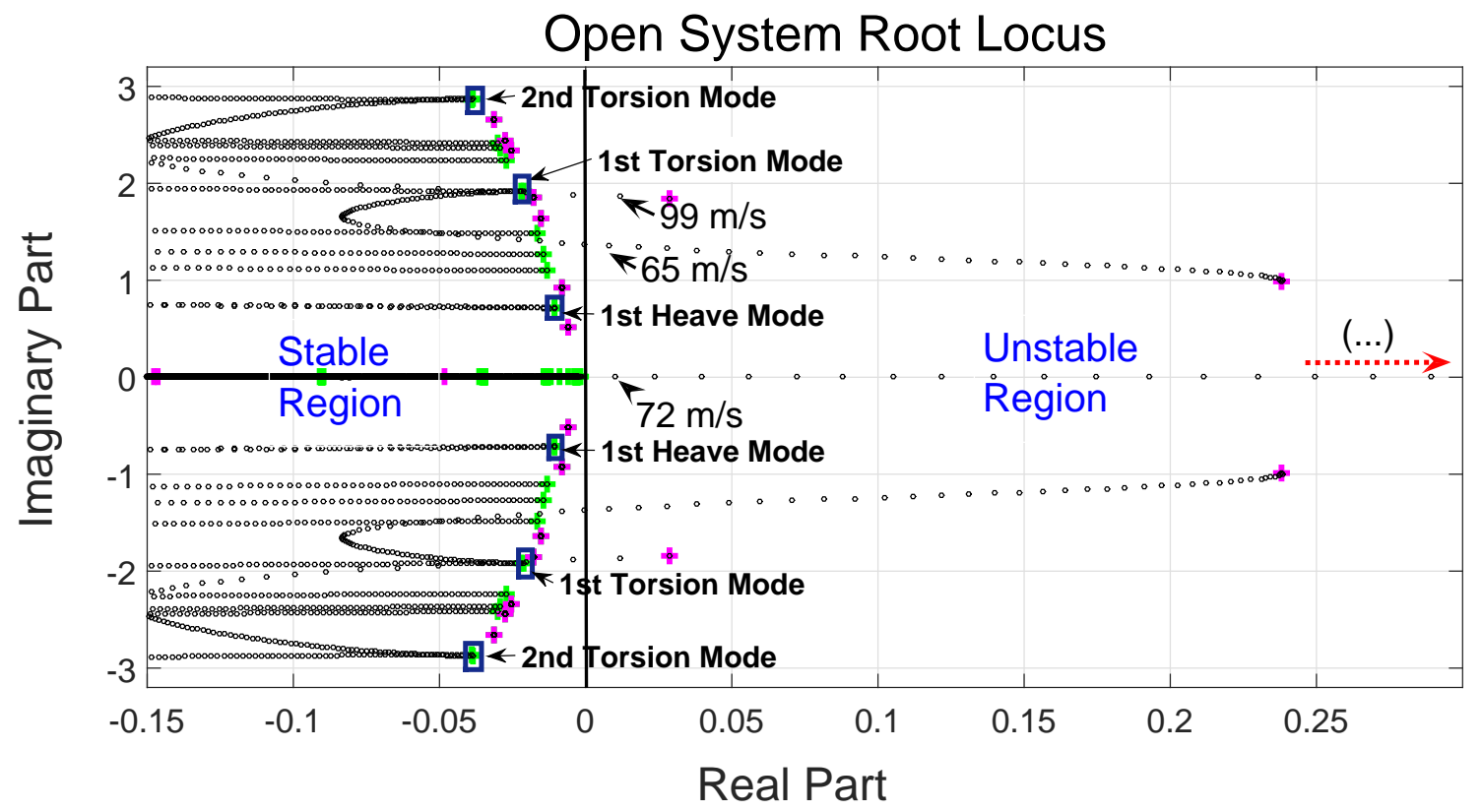

Figure 11: Root locus of the Humber Bridge. The wind speed is swept from $0 \mathrm{~m} / \mathrm{s}$ to $100 \mathrm{~m} / \mathrm{s}$, with the low-speed end marked with a green plus and the high-speed end with a magenta plus. The first flutter mode, starting at $0 \mathrm{~m} / \mathrm{s}$ as the 1 st torsion mode, becomes unstable at $65 \mathrm{~m} / \mathrm{s}$. Torsional divergence instability occurs at $72 \mathrm{~m} / \mathrm{s}$.

It can be observed that as wind speed increases, the damping of the heave modes increases and the corresponding complex pair of eigenvalues moves further into the stable left-half plane. The first torsional mode, although stabilized at moderate winds becomes unstable when wind speed reaches $65 \mathrm{~m} / \mathrm{s}$. Similarly, the second torsional mode reaches the flutter boundary at $99 \mathrm{~m} / \mathrm{s}$. There is also a real structural mode that represents pitching of the bridge deck due to steady-state aerodynamic moment, this is the torsional divergence mode. When wind speed exceeds $72 \mathrm{~m} / \mathrm{s}$ the bridge deck assuming linear behaviour will monotonically diverge in a pitching motion. In mechanical terms the bridge's torsional stiffness is 'cancelled out' by the pitch-related aerodynamic moment. The critical flutter speed estimation using thin aerofoil theory is in agreement with the experimental investigation given by Diana et al. [38], in which the flutter speed is estimated at $57 \mathrm{~m} / \mathrm{s}$ with an accumulated error of $12 \%$. In this analysis the structural damping matrix is derived assuming a Rayleigh proportional damping model $C=a_{M} M+a_{K} K$. The parameters $a_{M}, a_{K}$ are chosen so as to result in a $1 \%$ critical damping ratio for the first vertical and torsional mode in the completed stage and $0.5 \%$ during the intermediate erection stages.

Fig. 12 shows the evolution of the natural frequencies and damping ratios for the first two torsional modes and the first four vertical modes. It can be observed that at in the vicinity of the first flutter speed at $65 \mathrm{~m} / \mathrm{s}$ the natural frequencies of the first vertical symmetric, the first torsional symmetric and the second vertical symmetric converge in value. It is however the damping ratio of the first torsion mode that becomes negative at the critical flutter wind speed, whereas the damping of the vertical modes increases with increased wind speed. Similarly for the second flutter mode it is seen that the natural frequencies of the second torsion mode, the first vertical antisymmetric mode and the first symmetric vertical mode converge in value near the second critical flutter speed.

A similar procedure is followed during erection the of the Humber Bridge. Fig. 13 shows the modes shape of the first vertical symmetric mode during the erection process with reference to the completed Humber Bridge. As a result of modelling assumptions, the vertical displacement of the deck is assumed equal to the vertical displacement of the cables. For visualisation purposes, the cable displacement at locations where the deck is yet to be erected is shown 
as a deck displacement in Fig. 13. This symmetric erection process mimics the actually deck construction procees as reported in [36] and [43]. The flutter and torsional divergence stability limits are shown in Fig. 14 for the adopted erection process. The flutter limits reported in Brancaleoni [36] are superimposed on the figure for comparison.
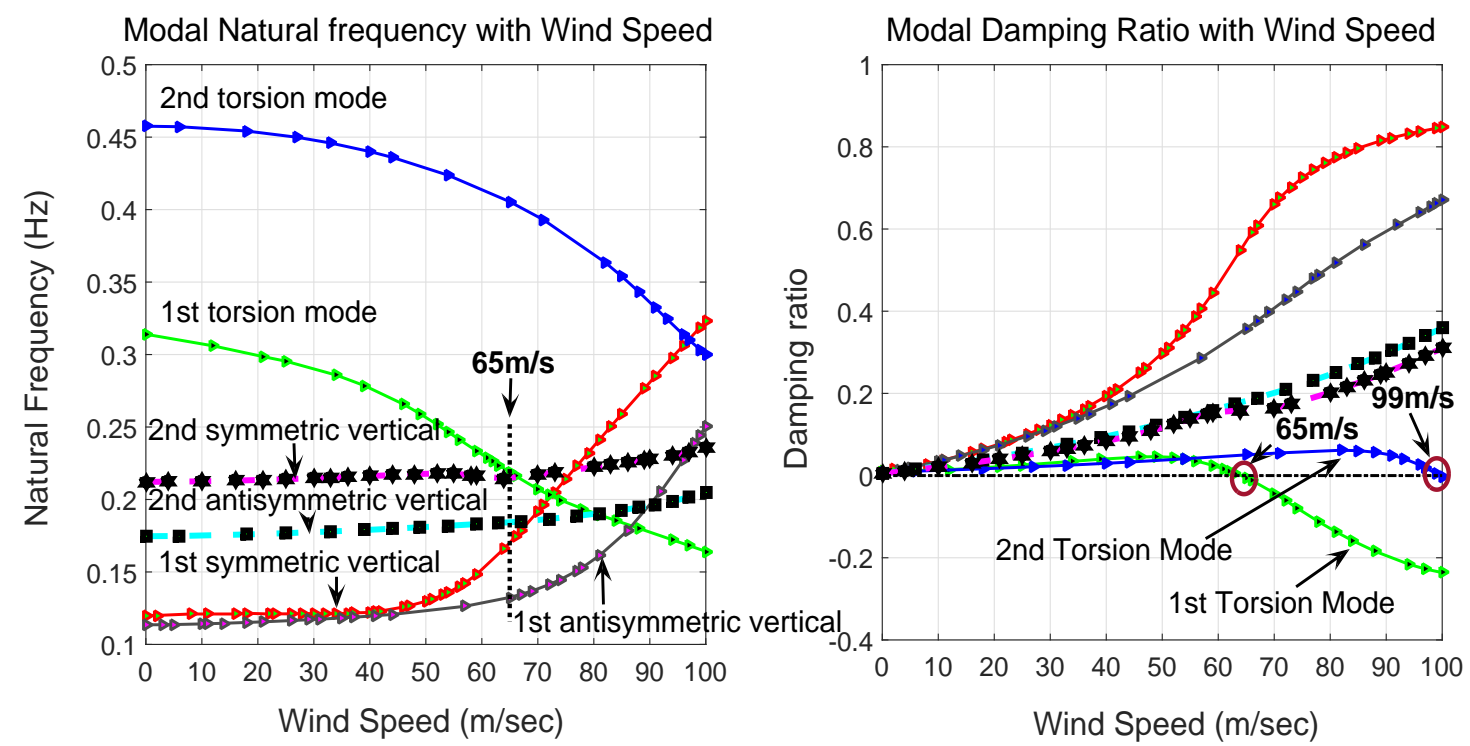

Figure 12: Evolution of the natural frequencies and damping ratios for the first two torsional modes and the first four vertical modes with the wind speed swept from $0 \mathrm{~m} / \mathrm{s}$ to $100 \mathrm{~m} / \mathrm{s}$.

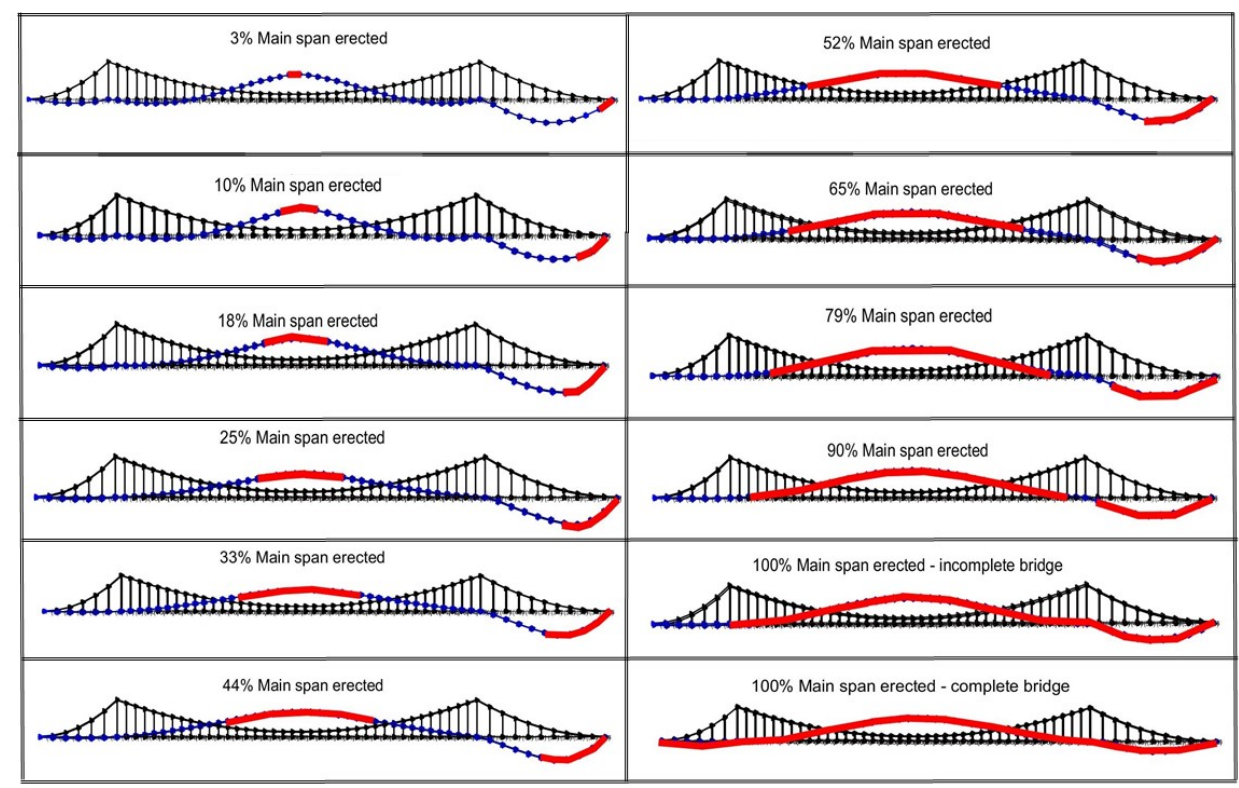

Figure 13: Humber Bridge, mode shape evolution of first symmetric vertical mode for different erection stages. Erected deck segments denoted by red solid line.

Thin airfoil theory appears to estimate the critical flutter speed with good accuracy, see Diana et al. [38]. Good 


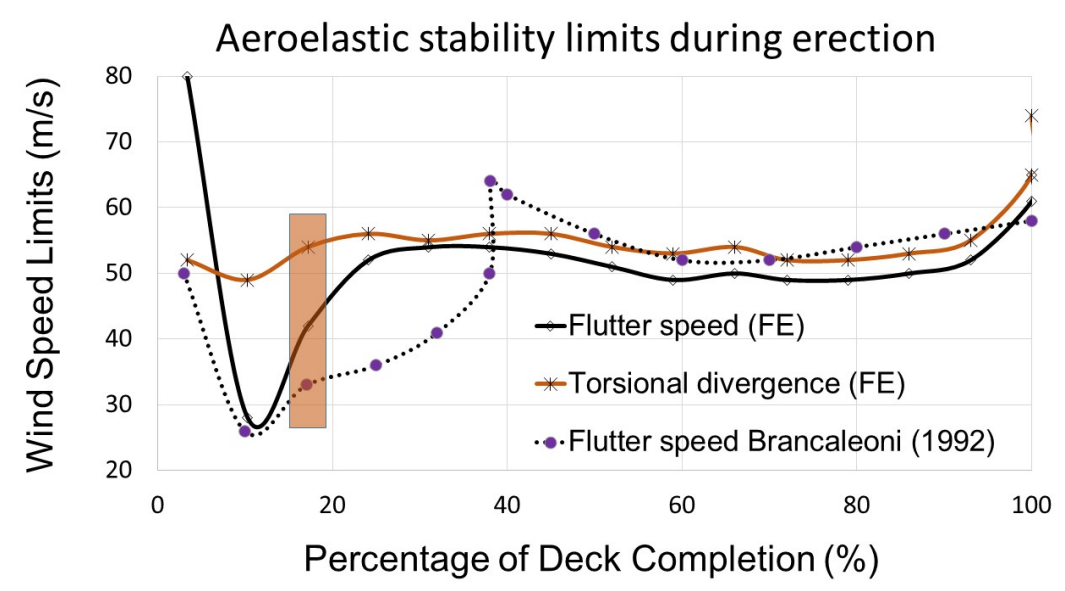

Figure 14: Aeroelastic stability limits as a function of deck percentage completion.

agreement is also shown in [19] for the case of the East Great Belt Bridge, where thin airfoil theory and the experimentally derived flutter derivatives framework [44] are compared. In [45] the applicability of thin aerofoil theory for modelling streamlined girders was further elaborated using wind tunnel experiments. In this study the derivatives of a flat box girder deck model were extracted and compared with the theoretical predictions, fair agreement was observed between theoretical and measured derivatives. It is thus expected that airfoil theory will be reasonably accurate for all streamlined box girder bridge structures.

During the erection process the evolution of the bridge's stability characteristics is related to the interplay between the critical modal frequencies and their mode shapes. It has become evident that there is a strong correlation between the torsion/heave frequency ratio, as shown in Fig. 6, and the first flutter mode stability limits presented in Fig. 14. The abrupt change in the flutter curve of Fig. 14 is associated with the change in the first torsional mode illustrated in Fig. 7; this change is apparently a result of increased deck inertia. The distinct peak reported in Brancaleoni [36] is not reproduced by the present aeroelastic model, which recognises the full-bridge multimodal interactions, and consequently, results in a more realistic and accurate prediction of the stability limits. The results do, however, show that the Humber Bridge exhibits low critical flutter speed at 10-20\% completion. When the partially erect deck is short, the oscillating mass is large because of the mass of the cables and a large structural inertia results. Also, a short deck section results is relatively small aerodynamic forces, which explains why the flutter speed is high in the early stages of construction. At reduced torsional stiffness the vertical and torsional vibration frequencies are close together. As the aerodynamic forces increase with increased deck length the flutter speeds drops drastically [39].

\section{Reduced Order Structural and Aerodynamic Model}

The flap controller design optimisation process requires the use of a nonlinear programming algorithm, which can be expensive to run in terms of computing resources. Given that the system model has hundreds of states, significant practical design benefits derives from the use of a reduced-order system model.

\subsection{Dominant Poles and Modal Equivalent}

Suppose we are given a $n^{\text {th }}$ order time invariant descriptor multi-input multi-output system (MIMO) $\left(E_{f}, A_{f}, B_{f}, C_{f}\right)$ of the form:

$$
\left\{\begin{array}{l}
E_{f} \dot{x}_{f}=A_{f} x_{f}+B_{f} u \\
z=C_{f} x_{f}
\end{array}\right.
$$


where, $E_{f}, A_{f} \in \mathbb{R}^{n \times n}, B_{f} \in \mathbb{R}^{n \times m}, C_{f} \in \mathbb{R}^{p \times n}, x_{f} \in \mathbb{R}^{n}, u \in \mathbb{R}^{m}$ and $z \in \mathbb{R}^{p}$. The model reduction problem is to find a stable $k^{\text {th }}$ order system $\left(\tilde{E}_{f}, \tilde{A}_{f}, \tilde{B}_{f}, \tilde{C}_{f}\right)$ :

$$
\left\{\begin{array}{l}
\tilde{E}_{f} \dot{\tilde{x}}_{f}=\tilde{A}_{f} \tilde{x}_{f}+\tilde{B}_{f} u \\
\tilde{z}=\tilde{C}_{f} \tilde{x}_{f},
\end{array}\right.
$$

where $k \ll n$, and $\tilde{E}_{f}, \tilde{A}_{f} \in \mathbb{R}^{k \times k}, \tilde{B}_{f} \in \mathbb{R}^{k \times m}, \tilde{C}_{f} \in \mathbb{R}^{p \times k}, \tilde{x}_{f} \in \mathbb{R}^{k}, u \in \mathbb{R}^{m}$ and $\tilde{z} \in \mathbb{R}^{p}$. The number of inputs and outputs are hence the same as for the original system. The model reduction process implemented in this work is based on the premise that the reduced-order model is constructed via a Petrov-Galerkin projection:

$$
\left(\tilde{E}_{f}, \tilde{A}_{f}, \tilde{B}_{f}, \tilde{C}_{f}\right)=\left(Y^{*} E_{f} X, Y^{*} A_{f} X, Y^{*} B_{f}, X^{*} C_{f}\right)
$$

where $X, Y \in \mathbb{R}^{n \times k}$ are matrices whose columns form the bases of relevant subspaces in the state-space. The procedure adopted in this paper is that of the dominant pole algorithm (DPA) first proposed by Martins et al. [46]. The transfer function $G(s)$ of the system in Eq.(16) is given by:

$$
G(s)=C_{f}\left(s E_{f}-A_{f}\right)^{-1} B_{f}
$$

where $s$ is the Laplace variable. The poles of the transfer function (19) are the eigenvalues $\lambda_{i} \in \mathbb{C}$ of the matrix pencil $\left(A_{f}, E_{f}\right)$, some of which might be at infinity. An eigentriplet $\left(\lambda_{i}, v_{i}, w_{i}\right)$ contains an eigenvalue as well as the right and left eigenvectors $v_{i}, w_{i} \in \mathbb{C}^{n}$ :

$$
\left\{\begin{array}{l}
A_{f} v_{i}=\lambda_{i} E_{f} v_{i}, \\
w_{i}^{*} A_{f}=\lambda_{i} w_{i}^{*} E_{f},
\end{array}\right.
$$

If the pencil has a simple eigenstructure, non repeated eigenvalues, then the transfer function can be expressed as a sum of residue matrices $R_{j} \in \mathbb{C}^{p \times m}$ over the first order poles [47, 46]:

$$
G(s)=R_{\infty}(s)+\sum_{j=1}^{\tilde{n}} \frac{R_{j}}{s-\lambda_{j}}
$$

Where, $\tilde{n} \leq n$ is the number of finite poles (eigenvalues), and $R_{\infty}(s)$ is the contribution due to poles at infinity. It can be therefore concluded that $G(s)$ can be effectively approximated by the sum of $k<\tilde{n}$ terms, which have the largest residue magnitudes $\left|R_{j}\right|$. The reduced sum of $k$ terms determine the so called effective transfer function [46]. This means that the peaks of the Bode magnitude plots occur at frequencies close to the imaginary parts of the dominant poles of $G(s)$. Hence, an approximation of $G(s)$ consisting of $k$ terms with the largest $\left|R_{j}\right|$ defines the approximation, modal equivalent.

$$
G_{k}(s)=\sum_{j=1}^{k} \frac{R_{j}}{s-\lambda_{j}}
$$

In general, dominant poles can be located anywhere in the $\left(A_{f}, E_{f}\right)$ spectrum. The proposed algorithm in [46] converges to the dominant poles of a single-input single-output system (SISO) using initial guesses, shifts. A modal equivalent that consists of the most dominant terms determines the effective transfer function behaviour. if $X \in \mathbb{C}^{n \times k}$ and $Y \in \mathbb{C}^{n \times k}$ contain the right and left eigenvectors $v_{i}$ and $w_{i}$ of $\left(A_{f}, E_{f}\right)$ as column vectors, such that $Y^{*} A X=\Lambda=\operatorname{diag}\left(\lambda_{1}, \ldots, \lambda_{k}\right)$ and $Y^{*} E_{f} X=I$, then the reduced system can be derived as follows by setting $x=X \tilde{x}$ and left multiplying by $Y^{*}$ :

$$
\left\{\begin{array}{l}
\dot{\tilde{x}}_{f}(t)=\Lambda \tilde{x}_{f}(t)+\left(Y^{*} B_{f}\right) u(t) \\
\tilde{z}(t)=\left(C_{f} X\right) \tilde{x}_{f}(t),
\end{array}\right.
$$

For stable systems, the error in the modal equivalent can be quantified as follows [48]: . For this study the flap surfaces were assumed to have a thickness of $2 \mathrm{~cm}$, which was deemed sufficient to avoid aerodynamic instabilities of the flaps themselves, e.g. torsional divergence. The flap small thickness justifies the assumption of thin aerofoil theory. The flap resonant frequencies about their hinges $\omega_{\beta}$ and $\omega_{\gamma}$ dependent on selected retention components, spring stiffness, and were chosen so that the flaps are stable at wind speeds well beyond the aeroelastic limits of the bridge structure. In a practical implementation of flap surfaces it is aerodynamically useful to consider the trailing flap to have a thin 
triangular section and the leading flap to have rounded NACA profile to suppress the leading-edge separation that would otherwise occur. Further insight into the practical implementation of this system in a wind tunnel setup is presented in [45].

For controller design purposes we seek to maximize the robust stability margins in a sense to be described. The higher the stability robustness margin, the larger the uncertainties (e.g. variations in the model and/or in its parameters) that the controlled system can maintain stable. A key assumption in the system modelling is that the uncertain part of the process can be modelled separately from the known nominal model of the process. This is a form of unstructured uncertainty and does not relate to specific mechanical components or system parameters [49].

In this work we will use a left normalised coprime factor description of the plant $[49,48]$ as the basis for the robust stability optimisation process. It is possible to represent any proper real-rational transfer function in terms of a pair of asymptotically stable, proper real-rational transfer functions that are left coprime. Suppose the plant model's associated transfer function is given by the left-coprime description $G=\tilde{M}^{-1} \tilde{N}$; a comprehensive treatment of the factorization of transfer functions is given in [50]. Let $G_{\Delta}$ be the transfer function of the perturbed plant model, and suppose that $\Delta_{N}, \Delta_{M}$ are stable unknown transfer functions that provide an uncertainty description such that $G_{\Delta}=\left(\tilde{M}+\Delta_{M}\right)^{-1}\left(\tilde{N}+\Delta_{N}\right)$. If $\varepsilon>\left\|\Delta_{M} \Delta_{N}\right\|_{\infty}$ is a maximum size of a perturbation that can be accommodated without destabilizing the closed-loop system, the system is said to be robustly stabilizable with stability margin $\varepsilon$. The objective of the design process is to generate controllers that guarantee a level of robust stability in the closed-loop system. This robust stabilization problem is expressible as an $H_{\infty}$ optimization problem, where the controller $K$ is chosen to minimize the $H_{\infty}$ norm of a closed-loop transfer function, under the constraint that it must also stabilize the nominal plant [51]. For the normalized left coprime factorization of $P$ the largest positive stability margin attainable $\varepsilon=\varepsilon_{\max }$ is given by Eq.(24), [48]. In practice the objective is to find a stabilizing feedback controller which maximizes $\varepsilon$.

$$
\varepsilon_{\text {max }}=\left(\gamma_{\text {min }}\right)^{-1}=\left\{\inf _{K}\left\|\left[\begin{array}{c}
K \\
I
\end{array}\right](I-G K)^{-1}\left[\begin{array}{ll}
I & G
\end{array}\right]\right\|_{\infty}\right\}^{-1}=\sqrt{\left(1-\|\tilde{M} \tilde{N}\|_{H}^{2}\right)},
$$

where $\|\cdot\|_{H}$ denotes the Hankel norm. The normalized coprime factor model is a an attractive way of modelling uncertainty, because it allows a general class of errors to be considered and no limitation is placed on the number of right-half plane poles in the perturbed plant [48].

In this study we will confine our attention to passive control systems that do not require power supplies. A mechanical one-port network with a moment-velocity pair $(M, v)$ is defined as positive real (passive) if for all admissible $M$ and $v$

$$
\int_{-\infty}^{T} M(t) v(t) d t \geq 0
$$

is satisfied; this condition says that the one-port is incapable of generating energy [52]. In the case of the one-ports considered here, the flap moments $M_{c}^{\beta_{l}}$ and $M_{c}^{\beta_{t}}$ are the through variables, with the angular rates $\dot{\beta_{l}}$ and $\dot{\beta_{t}}$ being the across variables [52]. The concept of through and across variables originates from electrical networks and motivates the well known force-current analogy that allows these ideas to be translated into a mechanical network setting [53].

In a further narrowing of the problem, we focus on the synthesis of first-order compensators for the flap controllers that seek to maximise the robustness index $\varepsilon$. Higher order compensators were examined, but the additional benefits were found to be minimal. Fig. ?? is a conceptual sketch of the passive mechanism's practical implementation. The transfer functions $Y_{g l}(s)$ and $Y_{g t}(s)$ are mechanical networks that apply control torques to the leading-and trailing-edge flaps, respectively, in response to rates of change of flap angle.

The class of first-order compensators considered here are of the form

$$
K(s)=\frac{A s+B}{C s+D}
$$

where $A \geq 0, B \geq 0, C \geq 0$ and $D \geq 0$, with at least one of $C$ and $D$ positive. These compensators are said to be positive real, and can therefore be synthesised using passive components [52]. In order to ensure that the compensator synthesis optimization problem is properly posed, a number of constraints must be put in place:

1. the closed-loop eigenvalues must be constrained to have negative real parts; 
2. the compensators' gains may be constrained so that high-ratio gearboxes and large flap angles are avoided;

3. The compensators $K(s)$ are constrained to be passive (positive real) so that they can be synthesized using passive mechanical components [53].

In order to synthesise the controller, one recalls that the admittance (the ratio force/velocity) of a damper is constant, say $c$. The admittance of a spring is $k / s$ and the admittance of a an inerter is $b s$ [53]. Therefore, if one were to consider a damper and spring connected in parallel, the admittance of the combination would be $c+k / s$. Applying the basic rules associated with series and parallel combinations of mechanical elements, the admittance is the sum of the admittances for a parallel combination of elements, while the inverse of the sum of the inverses is used for a series combination. In the case of the first-order compensator (26), one observes that when $A D-B C>0$ :

$$
\begin{aligned}
K(s) & =\frac{A s+B}{C s+D}=\left(\frac{C s+D}{A s+B}\right)^{-1}=\left(\frac{C}{A}+\left(\frac{A(A s+B)}{A D-B C}\right)^{-1}\right)^{-1}= \\
& =\left(\frac{1}{A / C}+\left(\frac{A^{2} s}{A D-B C}+\frac{A B}{A D-B C}\right)^{-1}\right)^{-1}=\left(\frac{1}{c_{1}}+\left(b s+c_{2}\right)^{-1}\right)^{-1}
\end{aligned}
$$

which represents a damper $c_{1}=A / C$ connected in series with the parallel combination of a damper $c_{2}=A B /(A D-$ $B C)$ and an inerter $b=A^{2} /(A D-B C)$; see Fig. $15^{1}$. When $A \gg B$, the transfer function $K(s)$ can be approximated by an inerter and a damper in series.

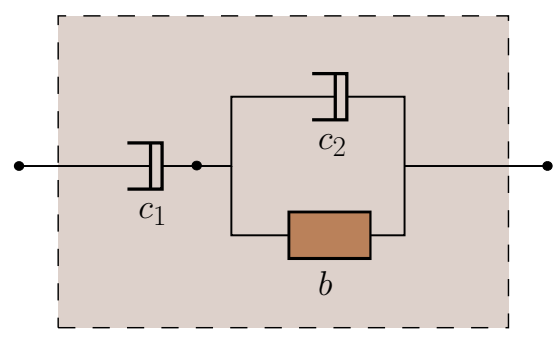

Figure 15: Realization of the first-order mechanical compensator (27).

\subsection{Structural and Controller Optimisation}

The aeroelastic stability properties of the uncontrolled deck are shown in Fig. 16 (a), where the flaps are rigidly attached to the deck. It is clear that the pitch-mode flutter mode of the open-loop system occurs at a wind speed of $65 \mathrm{~m} / \mathrm{s}$, whereas the torsional divergence mode becomes unstable at $72 \mathrm{~m} / \mathrm{s}$. These results are in excellent agreement with the FE model analysis, see Fig. 11, which shows that in case of the Humber bridge the first flutter mode involves predominately the coupling of the first heave mode and the first torsional mode and the contribution of the second vertical symmetric mode is small at the completed stage.

Fig. 16 (b) presents the system's performance with optimised flap retention components $K_{\beta}$ and $K_{\gamma}$, and $C_{\beta}$ and $C_{\gamma}$ in (3)-(4), as well as optimised flap pivot locations in Fig. ?? and additional first order mechanical compensators $K_{l}, K_{t}$, Fig. 15, in parallel with the spring-damper components. Design of flap retention components and optimal pivot locations as presented in Table 3 results in significantly increased flutter and torsional divergence speeds of $89 \mathrm{~m} / \mathrm{s}$ and $101 \mathrm{~m} / \mathrm{s}$ respectively. However the robustness properties were poor and the introduction of the control networks

\footnotetext{
${ }^{1}$ When $A D-B C<0$ there holds

$$
K(s)=\frac{A s+B}{C s+D}=\frac{A}{C}+\frac{B C-A D}{C(C s+D)}=\frac{A}{C}+\left(\frac{C^{2} s}{B C-A D}+\frac{C D}{B C-A D}\right)^{-1}=\frac{A}{C}+\left(\frac{1}{\frac{B C-A D}{C^{2} s}}+\frac{1}{\frac{B C-A D}{C D}}\right)^{-1}=c_{1}+\left(\frac{1}{\frac{k}{s}}+\frac{1}{c_{2}}\right)^{-1}
$$

which consists of a damper $c_{1}=A / C$ in parallel with the series connection of a spring $k=(B C-A D) / C^{2}$ and a damper $c_{2}=(B C-A D) / C D$
} 


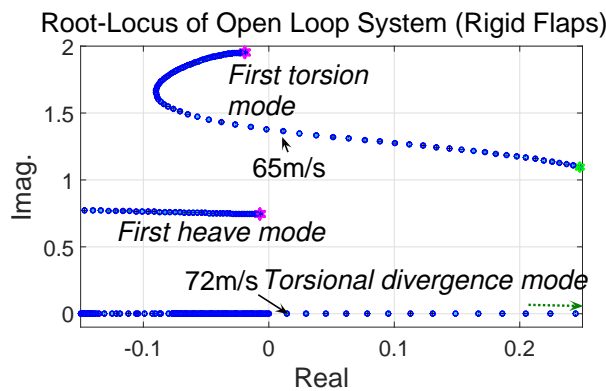

(a)

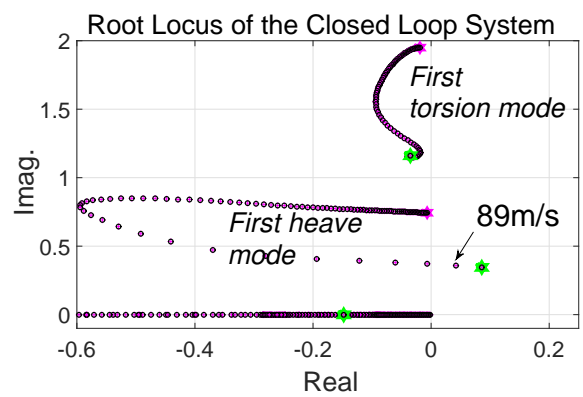

(b)

Figure 16: (a) Root-loci of the uncontrolled section model of the Humber Bridge. (b) Root-loci of the controlled section model of the Humber Bridge. The wind speed is swept from $0 \mathrm{~m} / \mathrm{s}$ to $90 \mathrm{~m} / \mathrm{s}$.

$K_{l}(s)$ and $K_{t}(s)$ significantly improves the systems robustness margins, while retaining the increased critical flutter and torsional divergences speeds. Since this added robustness is required at high wind speeds, the design wind speed is taken to be $89 \mathrm{~m} / \mathrm{s}$, which is the highest wind speed for which the open-loop system is stable. The design optimisation focuses on determining the four parameters in each of $K_{l}(s)$ and $K_{t}(s)$, so as to maximise $\varepsilon_{\max }$ in (24). Since we impose a first-order passivity constraint on the controller, the parameter optimisation is achieved using a nonlinear programming algorithm rather than the standard linear optimal coprime-factor robustness theory associated with (24). The optimal compensators are given in Table 3 with $\varepsilon_{\max }=0.2770$.

\begin{tabular}{||c||c||c||c||c||c||}
\hline Flutter Speed & Tor. divergence speed & Rob. Index & Max. Tor. Var. & Stiffness $K_{\beta}$ & Stiffness $K_{\gamma}$ \\
\hline $89 \mathrm{~m} / \mathrm{s}$ & $101 \mathrm{~m} / \mathrm{s}$ & 3.61 & $3 \%$ & $3.72 \times 10^{5} \mathrm{kNm} / \mathrm{m}$ & $1.67 \times 10^{5} \mathrm{kNm} / \mathrm{m}$ \\
\hline Damp. ratio $\zeta_{\beta}$ & Damp. ratio $\zeta_{\gamma}$ & Hinge position LF & Hinge position TF & Tranfer function LF & Tranfer function TF \\
\hline $1.4 \%$ & $1.6 \%$ & $l_{d}=0.98$ & $t_{d}=0.91$ & $\frac{1.34 \times 10^{6} s+135}{18.46 s+141.2}$ & $\frac{4.51 \times 10^{6} s+460}{69.16 s+305.7}$ \\
\hline
\end{tabular}

Table 3: Aeroelastic limits, robustness properties and flap compensator properties of the sectional deck-flap system. Notation, LF: Leading Flap, TF: Trailing Flap.

The choice of the robustness index based on coprime realization of the plant is justified, since it can be related to model's physical properties, although this relationship is a nonlinear one. To illustrate this point we examine the effect of reducing the natural torsional frequency at zero wind speed, which relates to the flutter mode's initial frequency. Fig. 17 demonstartes that the flap compensators given in Table 3 can maintain closed-loop stability when the deck's torsional frequency is reduced up to $3 \%$. For larger reduction in the torsional structural frequency, a 'soft flutter' type instability results with a resonant frequency of approximately $0.175 \mathrm{~Hz}$. 


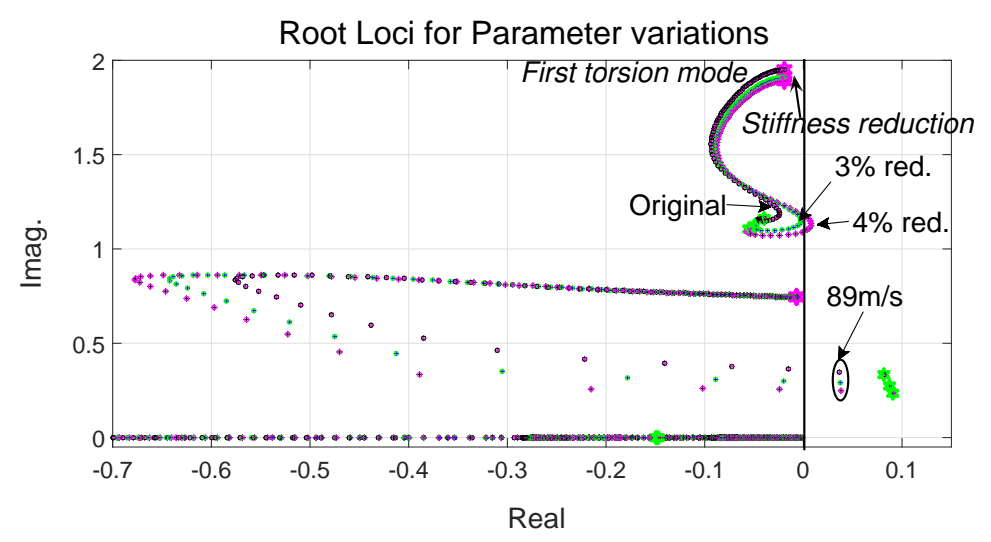

Figure 17: Root loci of the section deck-flap system for the nominal system, and for systems with $3 \%$ and $4 \%$ reductions in the (zero wind speed) structural torsional frequency.

\subsection{FE model of the deck-flap system and overall framework}

All the modelling and control system optimisation techniques are now in place; we provide an overview summary and flow diagram of the modelling and control system synthesis processes in Fig. 18. The first step is to develop a structural model that reproduces the bridge's important modal characteristics, both as a complete structure, and at various stages of the erection process; see Section 2. The kinematics of the flaps, which are connected to the deck by a spring and damper, are included as FE elements. The introduction of aerodynamic forces into the deckflap system can be achieved in two different ways. If the deck and winglets can be considered aerodynamically separate, flutter derivatives, obtained from wind tunnel experiments or CFD simulations, can be used to describe selfexcited forces on the deck; it is appropriate to model the winglets as thin aerofoils. Alternatively, if the deck and flaps interact aerodynamically, potential flow theory as developed by Theodorsen and Garrick [4, 41] can be used, following transformation [6], to describe the aeroelastic process dynamics. A reduced-order model of the MIMO system is then constructed using a two-step model reduction process. The first model-reduction step is directed to retaining the dominant modes of the system and removing the others; this process does not destroy the physical insight associated with the retained modes. The second model-reduction step uses standard balanced truncation [48] as is explained in Section 4. The reduced-order state-space description has the same number of inputs and outputs as the original system, but a significantly lower state dimension.

In order to introduce feedback control, the order of the compensator transfer function, at the flap connections, needs to be selected; first-order compensators are used here. These controllers are realised as a network of passive components that include springs, dampers and inerters [53]. The design optimisation of the parameters of the selected mechanical network components is achieved using a nonlinear programming code. Optimization constraints are introduced that ensure closed-loop stability, the passivity of the controller and introduce a limit to the compensator gain. Low controller gains are important, because high gains can cause large flap movements, which will in turn introduce flow separation that reduces the efficacy of the flaps. 


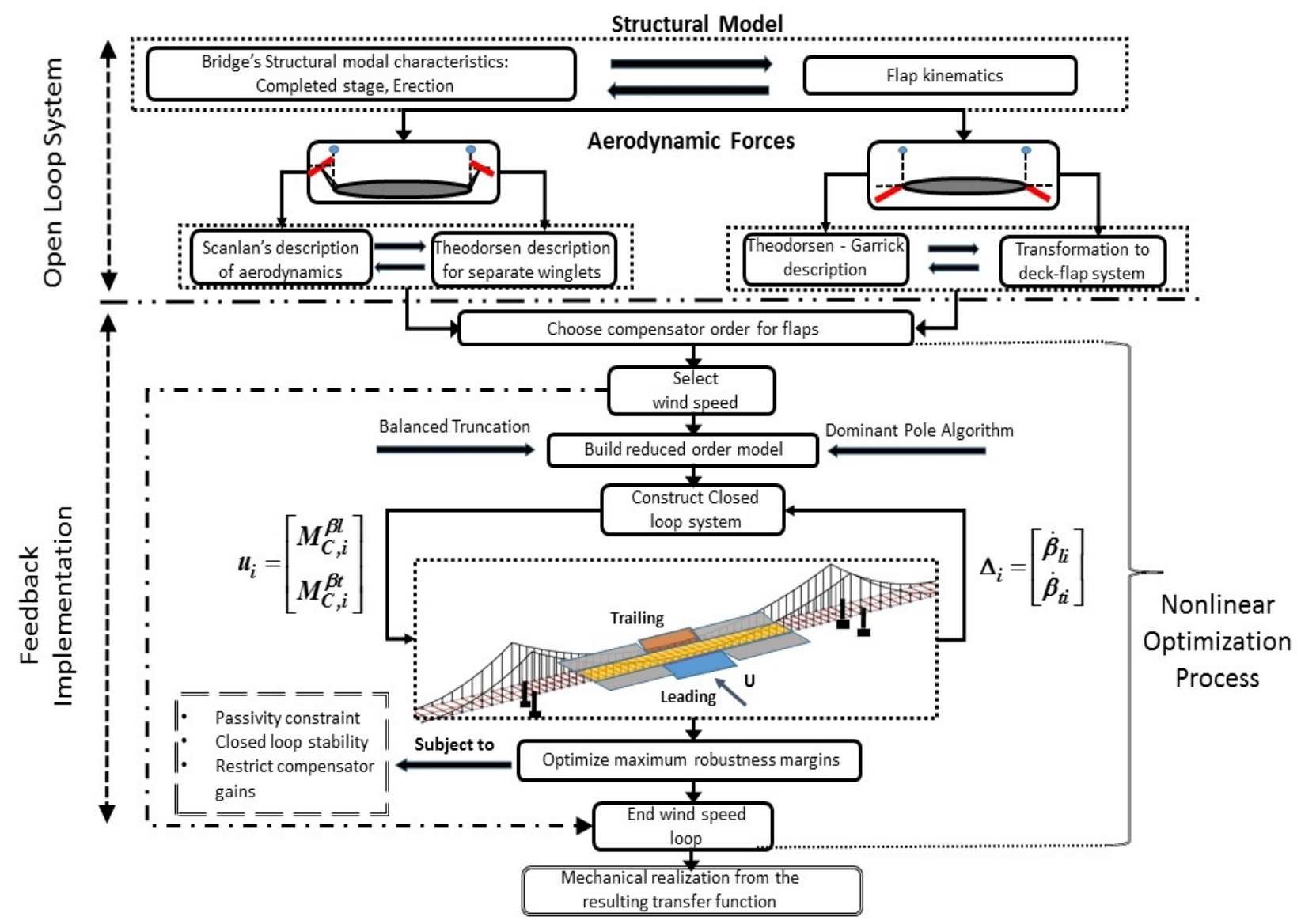

Figure 18: Controller-development flow diagram

\section{Control during deck assembly and completed stage}

The procedure described in the previous section is now used to examine the incomplete deck scenario. The $18 \%$ complete deck case (see Fig. ??) is used for illustration, since it represents a point of high vulnerability in the construction process. As is evident in Fig. 14, the critical flutter and divergence wind speeds are estimated as $42 \mathrm{~m} / \mathrm{s}$ and $53 \mathrm{~m} / \mathrm{s}$ using thin aerofoil theory; the flaps are assumed rigidly attached to the deck. These aeroelastic boundaries are significantly lower than the complete-structure values of $65 \mathrm{~m} / \mathrm{s}$ and $72 \mathrm{~m} / \mathrm{s}$ respectively; see Fig. 16 (a). Fig. 19 (a) shows the system root locus for the $18 \%$ complete deck; the unstable flutter and torsional divergence modes are clearly visible. Fig. 19 (b) presents the frequency and damping ratio of the flutter mode as a function of wind speed; the damping ratio becomes negative at $42 \mathrm{~m} / \mathrm{s}$ indicating instability at this wind speed. At zero wind speed, where the aerodynamic influences are small, the flutter natural frequency and damping ratio is that of the first structural torsion mode.

Fig. 20 shows the heave and torsional structural freedoms for the flutter mode as a function of wind speed. Since the phase information cannot be accurately conveyed in a diagram of this type, the magnitudes of the real parts of the appropriate eigenvector components have been plotted. At low wind speeds the heave motion is dominated by the second vertical symmetric mode, with the first vertical mode taking over at higher wind speeds. It is also evident from these figures that at all wind speeds the structural parts of the flutter mode are dominated by the fundamental torsion mode. The flat part of the torsion mode in the centre of the main span corresponds to completed section of the deck; see Fig. ??. The critical flutter speed for the equivalent heave-pitch system was computed at $32 \mathrm{~m} / \mathrm{s}$, which is very close to the flutter speed limit reported in the literature as reproduced in Fig. 14. The difference highlighted by the red 


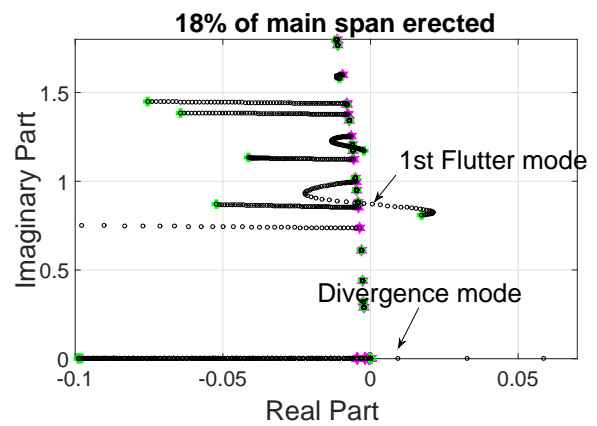

(a)
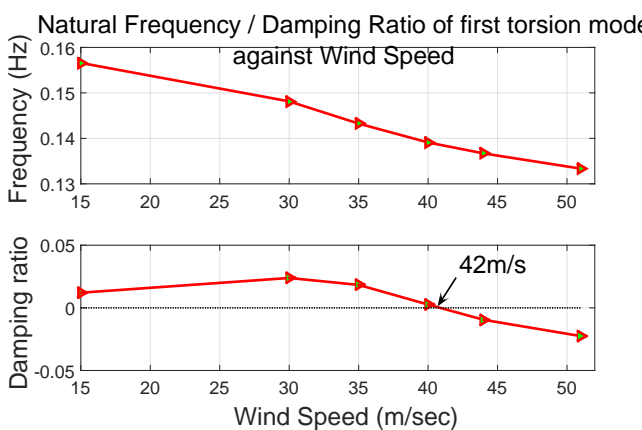

(b)

Figure 19: (a) Root locus of the Humber bridge when $18 \%$ of the main span is erected. The first and only flutter mode becomes unstable at $42 \mathrm{~m} / \mathrm{s}$. The torsional divergence mode reaches instability at $52 \mathrm{~m} / \mathrm{s}$. (b) Natural frequency $(\mathrm{Hz})$ and damping ratio of the first torsion mode (flutter mode) as a function of wind speed.

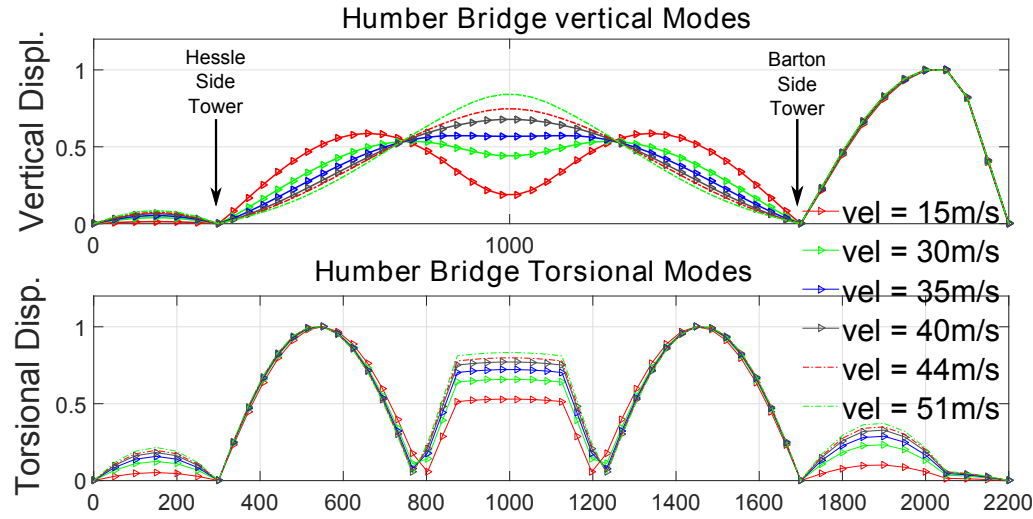

Figure 20: The heave and torsional components of the first flutter mode as a function of wind speed.

panel suggests that the higher order modes have a significant and in this case beneficial effect on the estimation of the flutter boundary.

The system used to increase the critical flutter speed at this stage of the construction comprises of movable leadingand trailing-edge flaps with a width of $2.75 \mathrm{~m}$ on either side of the central $180 \mathrm{~m}$ (five $36 \mathrm{~m}$ elements); of the $252 \mathrm{~m}$ (seven $36 \mathrm{~m}$ elements) assembled main span. Since there are five flap-equipped FEs, the feedback system has 10 inputs and 10 outputs. The $10 \times 10$ controller matrix is diagonal, since the flap compensators are decoupled from each other; the same compensators are used on each of the 5 leading- and trailing-edge flaps. Following the analysis presented in Sec.??, the flap hinge connections are located at the outside flap edges $l_{d}=1, t_{d}=1$. In contrast to the 4 DOF study presented in Section 4.2, the mechanical compensators produced a negligible improvement in the system robustness and so were omitted in this case. The system's robustness to variations in its mechanical properties did, however, improve as compared to the its 4-DOF counterpart. Fig.21 shows that the closed-loop system has a critical flutter speed of $62 \mathrm{~m} / \mathrm{s}$ and a critical divergence speed of $82 \mathrm{~m} / \mathrm{s}$. In order to assess the system stability robustness, the structural stiffness matrix was perturbed from its nominal value with calculations showing that a $\pm 6 \%$ variation in stiffness can be tolerated for wind speeds up to $62 \mathrm{~m} / \mathrm{s}$. In the case of a $6 \%$ decrease in stiffness, one is on the 'soft flutter' stability boundary. In this case flutter locus starts from the first structural (vertical) heave mode as opposed to the first torsion (pitch) mode as seen in Fig. 16 (a).

Fig. 22 shows the efficacy of the flap support components $K_{\beta}$ and $K_{\gamma}$, and $C_{\beta}$ and $C_{\gamma}$ in (3) and (4). The deck 


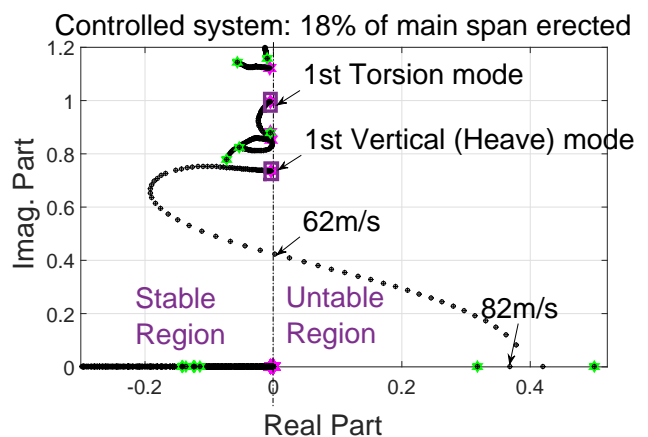

(a)

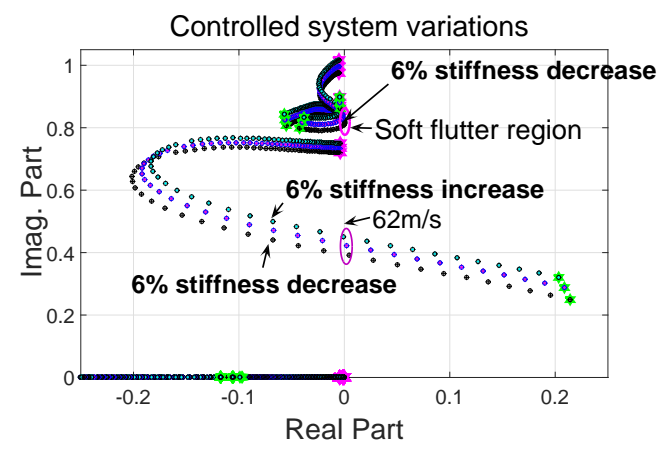

(b)

Figure 21: (a) Root loci for the controlled 18\% erected main span. The wind speed is swept from 0 to $83 \mathrm{~m} / \mathrm{s}$. The critical flutter speed is computed at $62 \mathrm{~m} / \mathrm{s}$ and the torsional divergence speed at $82 \mathrm{~m} / \mathrm{s}$. The flap retention network is comprises of single springs and dampers in parallel with values: $K_{\beta}=0.56 \times 10^{5} \mathrm{kNm} / \mathrm{m}, K_{\gamma}=1.47 \times 10^{5} \mathrm{kNm} / \mathrm{m}, \zeta_{\beta}=0.47 \%, \zeta_{\gamma}=0.77 \%$ (b) Root loci of the nominal closed-loop system with variation of $\pm 6 \%$ in the structural stiffness matrix. Wind speed is swept from 0 to $70 \mathrm{~m} / \mathrm{s}$.

response corresponds to an initial twisting of the main deck by $2^{\circ}=0.035 \mathrm{rad}$ its midpoint; the wind speed is $U=$ $51 \mathrm{~m} / \mathrm{s}$, which is above the open-loop frozen-flap critical flutter speed of $42 \mathrm{~m} / \mathrm{s}$; the influence of the flap support components is clear.
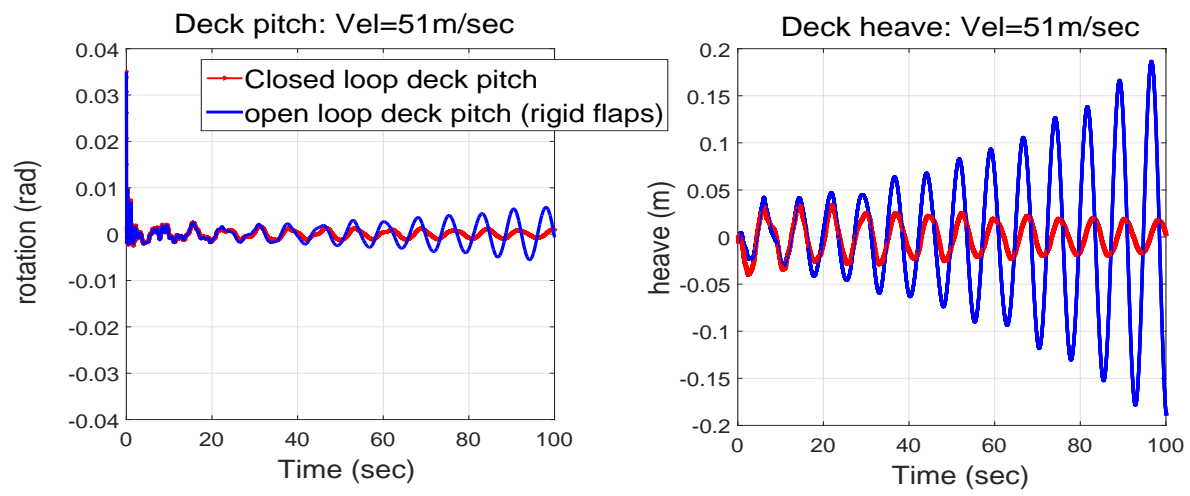

Figure 22: Time response of heave and pitch for the uncontrolled and controlled $18 \%$ erected deck at wind speed $U=51 \mathrm{~m} / \mathrm{s}$.

In an attempt to keep the further analysis simple, the network designed for the $18 \%$ case is used at other midconstruction phases. Fig. 23 demonstrates the efficacy of the flap support components on the aeroelastic limits during several deck assembly stages. The percentage of flap length, in terms of the main-span length, used at every stage is also indicated in the graph, maximum amount of flap length is $33 \%$ of the main span implemented symmetrically around the midpoint.

In Section 4.2 we observed that the proper selection of the spring stiffnesses $K_{\beta}$ and $K_{\gamma}$, the damping constants $C_{\beta}$ and $C_{\gamma}$ in (3) and (4) as well as the flap pivot locations in Fig. ?? would significantly increase the critical flutter speed. However, without an external control network, the system had poor robust stability margins. It is apparent from Fig.23 that this lack of robustness is again evident. While the flap retention components are effective in increasing both the critical flutter and divergence speed at early stages of construction, their efficacy reduces as the bridge construction progresses beyond the $50 \%$-complete stage. As is evident from Fig. 23, towards the end of completion, the movable flaps are having a relatively small influence on increasing the critical flutter and divergence speeds. This is not entirely surprising, because the stiffness and damping parameter values were not re-calibrated for subsequent construction phases. Furthermore, strong multimodal behaviours are presented in the intermediate stages, with higher 


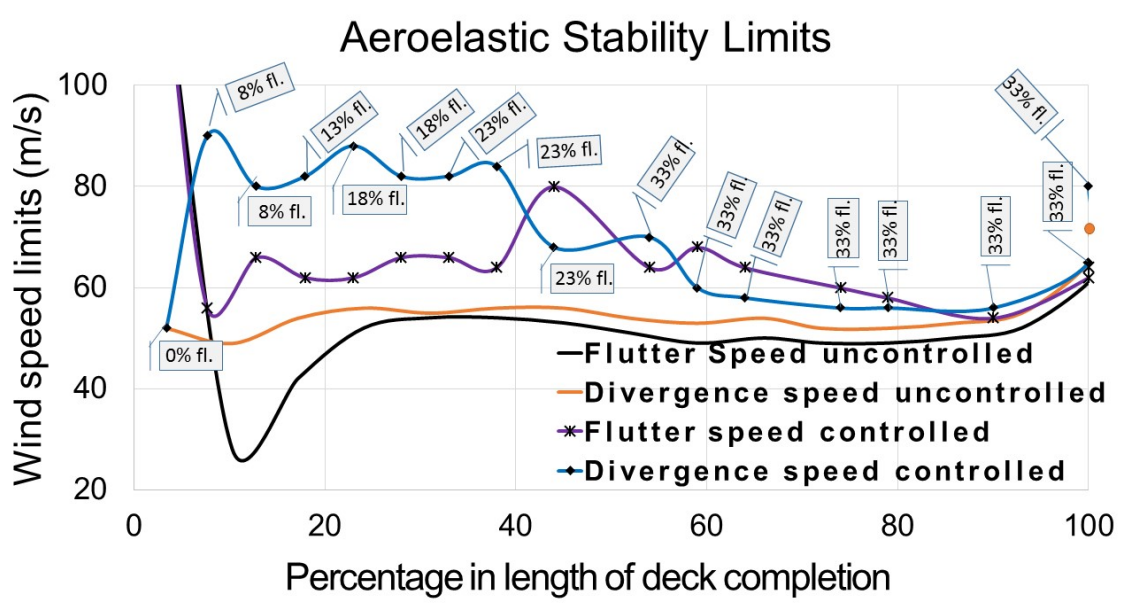

Figure 23: Aeroelastic stability limits against percentage deck completion for the rigid flap and movable flap cases. The flap support components are those determined in the $18 \%$ completion study. The length of the leading- and trailing-edge flaps in each erection stage is indicated as a percentage of the main span length ( $\mathrm{fl}=$ flap length), and the flap width is $2.75 \mathrm{~m}$.

flutter modes reaching instability at wind speeds close to the first critical flutter speed. The instability of these modes takes place in a narrow wind speed band, a fact that poses difficulty in control design when the control law for the leading and trailing flap compensators respectively is kept the same. In other words, without flap differential movement it is difficult to suppress multiple instability modes related to the coupling of higher structural modes[54]. Given the complex dynamical nature of the problem it is important during the controller design process to establish that there is no flap dynamic interaction with higher vibrational modes causing a different flutter mode to occur at a lower wind speed. A multi-modal framework and a reliable model reduction procedure is consequently of high importance. At final deck completion, the computed flutter speed is only $U=64 \mathrm{~m} / \mathrm{s}$, which is slightly lower than the uncontrolled (rigid flap) flutter speed of $U=65 \mathrm{~m} / \mathrm{s}$; the rigid- and movable-flap divergence speeds are $U=72 \mathrm{~m} / \mathrm{s}$ and $U=80 \mathrm{~m} / \mathrm{s}$ respectively. If the passive networks given in Eq.(26) were designed for the complete bridge, with the flaps covering the middle $33 \%$ of the main span, the resulting aeroelastic limits are significantly improved. There is a step increase in the full-bridge critical flutter speed when the temporary end connections are replaced with permanent ones. Table. 4 summarizes these findings as well as the network mechanical properties.

\begin{tabular}{||c||c||c||c||c||c||}
\hline Flutter Speed & Tor. div. speed & Max. Stiff. Var. & Stiffness $K_{\beta}$ & Stiffness $K_{\gamma}$ & Damp. ratio $\zeta_{\beta}$ \\
\hline $102 \mathrm{~m} / \mathrm{s}$ & $84 \mathrm{~m} / \mathrm{s}$ & $7 \%$ & $5.29 \times 10^{5} \mathrm{kNm} / \mathrm{m}$ & $1.25 \times 10^{5} \mathrm{kNm} / \mathrm{m}$ & $0.25 \%$ \\
\hline Damp. ratio $\zeta_{\gamma}$ & Tran. fun. LF & Tran. fun. TF & LF network & TF network & $l_{d}=t_{d}$ \\
\hline & & & $\frac{c 1=22614 \mathrm{Nmsec} / \mathrm{radm}}{c 2=0.14 \mathrm{Nmsec} / \mathrm{radm}}-$ & $\frac{c 1=319090 \mathrm{Nmsec} / \mathrm{radm}}{\frac{c 2=0.18 \mathrm{Nmsec} / \mathrm{radm}}{6}-}$ & 1 \\
$0.56 \%$ & $\frac{0.59 \times 10^{6} \mathrm{~s}+356.9}{26.09 \mathrm{~s}+2507}$ & $\frac{3.66 \times 10^{7} \mathrm{~s}+815.5}{114.7 \mathrm{~s}+4452}$ & $\frac{b 235.3 \mathrm{kgm}^{2} / \mathrm{m}}{b=8221 \mathrm{kgm}^{2} / \mathrm{m}}$ & 1 \\
\hline
\end{tabular}

Table 4: Aeroelastic stability limits, robustness margin and mechanical compensator characteristics for the full controlled bridge FE model. The flaps span the central $33 \%$ of the main span.

Fig.24 illustrates the transient movement of the flaps following a deck pitch disturbance; three leading- and trailing-edge flaps in the FE model are illustrated. 

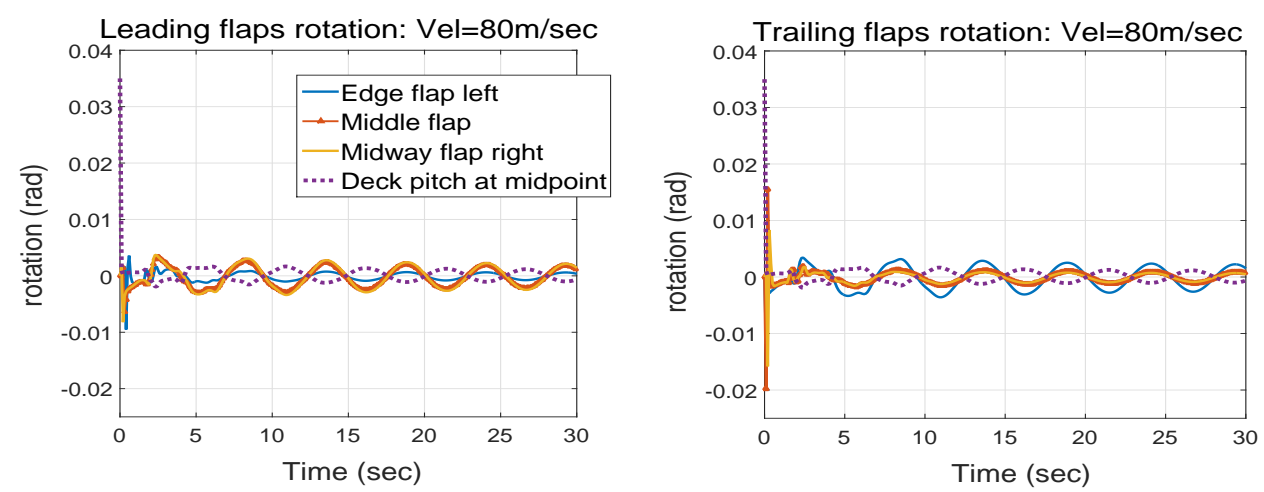

Figure 24: Flap angles transient response for the case of the completed bridge with flaps in the main $33 \%$ of the span.

The initial disturbance is a 0.035 rad twisting of the main span at the midpoint of the main span at a wind speed just below the critical divergence speed $(U=84 \mathrm{~m} / \mathrm{s}$ in this case). The resulting flap rotations are small compared to the deck's pitching motion justifying the assumption of 'small rotations' implicit in the use of thin airfoil theory.

As a final design study the aeroelastic stability limits during erection are re-computed following the introduction of re-tuned flap controllers that were introduced at four intermediate stages. The flap length distribution is kept the same as in Fig.23, with Fig.25 giving the results of re-tuning the mechanical network.

All the leading- and trailing-edge flaps used follow the same control law respectively. Although performance improvements are achieved in the intermediate stages between $50 \%$ and $100 \%$ complete, these improvements were not as significant as the introduction of compensation networks in the first instance. A more complicated control network distribution, with different controllers at each flap element, could potentially improve the system performance as this would help suppress higher flutter modes, prevalent in the intermediate stages. In sum, the final conclusion drawn is that the proposed mechanical network implementations presented in Fig.23 and Fig. 25 are relatively easy to implement and lead to a significant increase in the critical flutter and divergence speed at the early stages of erection and at the completed stage, after permanent connections are applied.

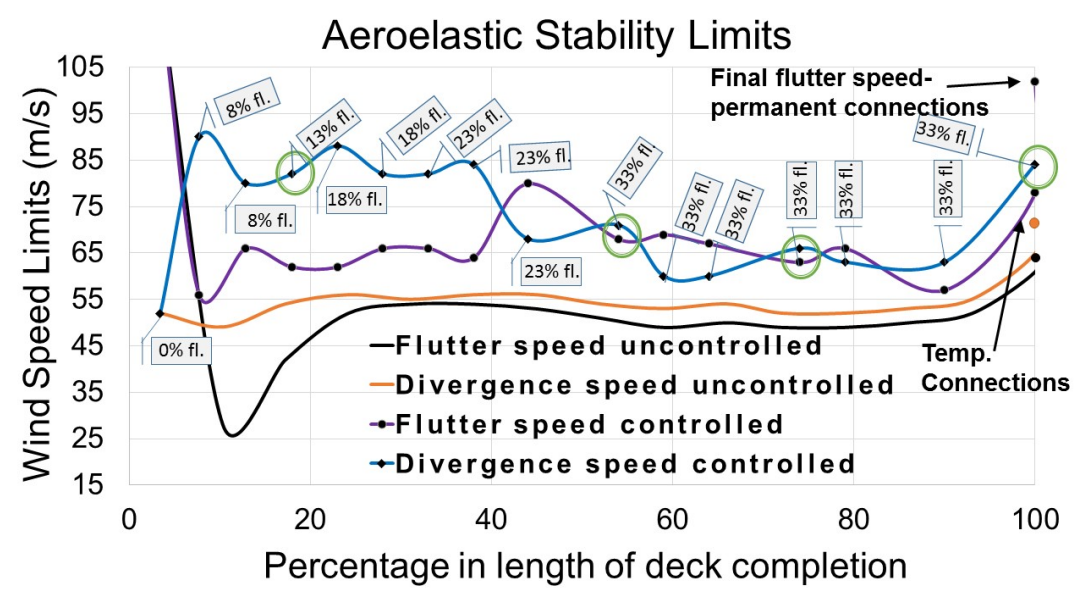

Figure 25: Aeroelastic stability limits against deck percentage completion for the uncontrolled, flaps rigidly attached to the deck, and the controlled deck. The implemented controllers were re-tuned at four intermediate stages, marked with green circles. The flap width is $2.75 \mathrm{~m}$.

More specifically, when $18 \%$ of the deck is completed the flutter boundary is raised from $42 \mathrm{~m} / \mathrm{s}$ to $62 \mathrm{~m} / \mathrm{s}$ and the divergence boundary from $54 \mathrm{~m} / \mathrm{s}$ to $82 \mathrm{~m} / \mathrm{s}$. This constitutes an increase of almost $50 \%$ when $13 \%$ of the entire 
main span is fitted with leading and trailing flaps. For the competed stage, after application of temporary connections, the flutter boundary is raised from $65 \mathrm{~m} / \mathrm{s}$ to $102 \mathrm{~m} / \mathrm{s}$ and the divergence boundary is raised from $72 \mathrm{~m} / \mathrm{s}$ to $84 \mathrm{~m} / \mathrm{s}$. This constitutes of a $29 \%$ increase of the total aeroelastic boundaries when the middle $33 \%$ of the main span is fitted with leading and trailing flaps. For the completed bridge the critical phenomenon is that of torsional divergence which appears to be difficult to control by means of limited flap aerodynamic surfaces. previous studies [55] using passive networks have shown a very limiting improvement of divergence limits while in [19] it was demonstrated that above the open loop divergence limit there is a rapid loss of the closed system's robustness properties. In this study however it is shown that when aerodynamic optimization using flaps is employed a significant increase in the divergence boundary can be attained even for a limited span of control surfaces.

\section{Conclusions}

This paper presents the overall framework for suppressing aeroelastic instabilities, with emphasis on flutter and torsional divergence, in long-span bridges by means of passively controlled leading- and trailing-edge flaps adjacent to the deck. The structural part of this work revisits a reduced size FE formulation for capturing the structure's modal properties. The contribution of both the girder and the main cables is combined into single straight structural elements, which simplifies analysis and reduces computational burden. The attained modal characteristics were compared to experimentally identified modes for the case of the Humber Bridge finding good agreement. The validation analysis transitioned to the modelling of the deck erection stage under the premise that a free unbraced suspended structure is more vulnerable to flutter instability. By reconstructing the deck assembly process of the Humber Bridge it was shown that the evolution of dynamic characteristics can be attained using slightly modified structural elements. In the aerodynamic part of this study classic results from potential flow theory were recast in a Laplace domain formulation implementing therein a rational function approximation of the circulatory fluid component for each structural element. The resulting model enables the estimation of the structure's aeroelastic characteristics while considering the full multi-modal interaction in a computationally efficient state space mathematical model. The obtained aeroelastic limits during the erection process show that the most vulnerable stages for flutter instability is when $10-20 \%$ of the main span is erected. This result is in agreement with previous analyses based on sectional models but also suggests that higher order modes have a beneficial effect on the critical flutter speed.

The control investigation is built upon a novel flap-deck system configuration, in which the flap retention components and flap pivot locations are determined via a nonlinear optimization code which seeks to maximize stability margins of the closed loop system. The proposed mechanical network has the advantages of: simultaneously increasing flutter and torsional divergence limits, being easily implementable as well as dispensing the need to be anchored in an inertial reference frame. Furthermore, the flap-deck connection avoids the use of external linkages and because of the nature of the feedback minimum interference with the deck's sway motion is anticipated. Further addition of an auxiliary first order mechanical compensator at the flap pivot points proved, in most cases, to significantly improve the system's stability margins. In addition, it was established that the mechanical network realization includes an inerter component suggesting that better performance is attained with increased apparent mass. Implementation of the proposed feedback mechanism to the bridge aeroelastic model proves its effectiveness during early stages of construction as well as during the completed stage. In effect, for the most critical erection stages approximately at $10-15 \%$ deck completion the critical flutter boundary is almost doubled and the critical divergence speed is increased about $50 \%$. In all cases, the flap span length was restricted to $33 \%$ of the main span. This flap coverage was deemed optimum for suppressing the first critical flutter mode which results from the interaction of symmetric torsional and vertical modes. Additional length of flap control surfaces would be beneficial in further increasing the torsional divergence boundary and also suppressing higher flutter modes, which would result from the interaction of antisymmetric vertical and torsional modes.

\section{Acknowledgements}

This work was partially funded by the IKY-State Scholarship Foundation by means of the ESPA European fund 2007-2013. the authors would also like to acknowledge the significant contribution of Dr. Matteo Massaro and Prof. Thomas Wyatt on this research. 


\section{References}

[1] K. Y. Billah, R. H. Scanlan, Resonance, Tacoma Narrows bridge failure, and undergraduate physics textbooks, American Journal of Physics 59 (2) (1991) 118-124.

[2] K. Wilde, Y. Fujino, Aerodynamic control of bridge deck flutter by active surfaces, Journal of Engineering Mechanics 124 (7) (1998) $718-727$.

[3] R. L. Bisplinghoff, H. Ashley, R. L. Halfman, Aeroelasticity, Dover Publications, New York, 1996.

[4] T. Theodorsen, General theory of aerodynamic instability and the mechanisms of flutter, NACA Report, TR-496.

[5] T. Theodorsen, I. E. Garrick, Nonstationary flow about a wing-aileron-tab combination including aerodynamic balance, NACA Report, TR736.

[6] J. M. R. Graham, D. J. N. Limebeer, X. Zhao, Aeroelastic control of long-span suspension bridges, ASME Journal of Applied Mechanics.

[7] K. N. Bakis, M. Massaro, M. S. Williams, J. M. R. Graham, Passive control of bridge wind-induced instabilities by tuned mass dampers and movable flaps, Journal of Engineering Mechanics submitted (2015) xx.

[8] A. Abdel-Ghaffar, Free vertical vibrations of suspension bridges, Journal of Structural Division ASCE 105(ST10) (1980) 2053-2076

[9] A. Abdel-Ghaffar, Free torsional vibrations of suspension bridges, Journal of Structural Division ASCE 105(ST4) (1979) 767-788.

[10] A. Abdel-Ghaffar, Free lateral vibrations of suspension bridges, Journal of Structural Division ASCE 104(ST3) (1978) 503-525.

[11] J. M. W. Brownjohn, M. Bocciolone, C. Curami, M. Falco, A. Zasso, Humber bridge full-scale measurement campaigns 1990-1991, Journal of Wind Engineering and Industrial Aerodynamics 52 (1994) 185-218.

[12] J. M. W. Brownjohn, F. Magalhaes, E. Caetano, A. Cunha, Ambient vibration re-testing and operational modal analysis of the Humber Bridge, Engineering Structures 32 (2010) 2003-2018.

[13] T. J. A. Agar, Aerodynamic analysis of suspension bridges by modal technique, Journal of Engineering structures 11 (1989) 75-82.

[14] A. Namini, Analytical modelling of flutter derivatives as finite elements, Journal of Computers and Structures 41(5) (1991) 1055-1064.

[15] M. A. Astiz, Flutter stability of very long span bridges, Journal of Bridge Engineering 3 (3) (1998) $132-139$.

[16] D. H. Hodges, G. A. Pierce, Introduction to structural dynamics and aeroelasticity, Cambridge Aerospace Series, 2002.

[17] P. Omenzetter, K. Wilde, Y. Fujino, Study of passive deck-flaps flutter control system on full bridge model 1: Theory, Journal of Engineering Mechanics March (2002) 264-279.

[18] X. Chen, M. Matsumoto, A. Kareem, Aerodynamic coupling effects of flutter and buffeting of bridges, Journal of Engineering Mechanics 126 (2000) 17-26.

[19] K. N. Bakis, M. Massaro, M. S. Williams, D. J. N. Limebeer, Aeroelastic control of long-span suspension bridges with controllable flaps, Journal of Structural Control and Health Monitoring.

[20] M. Massaro, J. M. R. Graham, The effect of three-dimensionality on the aerodynamic admittance of thin sections in free stream turbulence, Journal of Fluids and Structures 57 (2015) 81-90.

[21] G. Diana, C. Federico, Z. Alberto, A. Colina, S. Bruni, Aerodynamic design of very long-span suspension bridges, in: Long-Span and High-Rise Structures, IABSE Symposium, Kobe, 1998, pp. 115-130.

[22] H. F. Xiang, Y. J. Ge, On aerodynamic limit to suspension bridges, in: 11th International Conference on Wind Engineering, Texas USA, 2003.

[23] A. Larsen, T. Vejrum, S. Esdahl, Vortex models for aeroelastic analysis assessment of multi-element bridge decks, in: Bridge aerodynamics, Larsen\&Esdahl, Balkema,Rotterdam, 1998.

[24] K. Makoto, Technology of the Akashi Kaikyo Bridge, Journal of Structural Control and Health Monitoring 11 (2004) 75-90.

[25] K. Li, Y. J. Ge, Z. W. Guo, L. Zhao, Theoretical framework of feedback aerodynamic control of flutter oscillation for long-span suspension bridges by the twin-winglet system, Journal of Wind Engineering and Industrial Aerodynamics 145 (2015) $166-177$.

[26] K. H. Ostenfeld, A. Larsen, Bridge engineering and aerodynamics, in: Aerodynamics of Large Bridges, Proceedings of the First International Symposium on Aerodynamics of Large Bridges, Copenhagen,Denmark, 1992.

[27] D. Borglund, J. Kuttenkeuler, Active wing flutter suppression using a trailing edge flap, Journal of Fluids and Structures 16 (2002) $271-294$.

[28] E. L. Burnett, C. Atkinson, J. Beranek, B. Holm-Hansen, L. Nicolai, Ndof simulation model for flight control development with flight test correlation, in: Proc. AIAA Modelling Simulation Technology Conference, 2010, pp. 7780-7794.

[29] P. Omenzetter, K. Wilde, Y. Fujino, Suppression of wind-induced instabilities of a long span bridge by a passive deck-flaps control system part I: Formulation, Journal of Wind Engineering 87 (2000) 61-79.

[30] K. Wilde, Y. Fujino, Variable-gain control applied to aerodynamic control of bridge deck flutter, Proceedings of 35th Conference on Decision and Control, Kobe, Japan, 1996, pp. 682-687.

[31] X. Zhao, D. J. N. Limebeer, M. J. R. Graham, Modelling and control of a suspended-span bridge section, in: 19th World Congress, The International Federation of Automatic Control, Cape Town,South Africa, 2014.

[32] S. Kwon, K. S. Park, Suppresion of bridge flutter using tuned mass dampers based on robust performance design, Journal of Wind Engineering and Industrial Aerodynamics 92 (2004) 919-934.

[33] U. Starossek, H. Aslan, Passive control of bridge deck flutter using tuned mass dampers and control surfaces, in: 7th European Conference on Strcutural Dynamics, Southampton,United Kingdom, 2008.

[34] K. N. Bakis, M. Massaro, M. S. Williams, D. J. N. Limebeer, Aeroelastic control of long span suspension bridges during erection, in: IABSE conference, Elegance in Structures, Nara, Japan, 2015

[35] M. Massaro, K. N. Bakis, D. J. N. Limebeer, M. J. R. Graham, Flutter and buffeting of long span suspension bridges in fully erected and partially erected conditions, in: International Forum on Aeroelasticity and Structural Dynamics, Saint Petersburg, Russia, 2015.

[36] F. Brancaleoni, The construction phase and its aerodynamic issues, in: Aerodynamics of Large Bridges, A. Larsen, Rotterdam, Netherlands, 1992, pp. 147-158.

[37] F. Brancaleoni, D. M. Brotton, Analysis and prevention of suspension bridge flutter in construction, Journal of Earthquake Engineering and Structural Dynamics 9 (1981) 489-500.

[38] G. Diana, F. Cheli, A. Zasso, A. Collina, J. Brownjohn, Suspension bridge parameter identification in full scale test, Journal of Wind Engineering and Industrial Aerodynamics (1992) 165-176. 
[39] Y. J. Ge, H. Tanaka, Aerodynamic stability of long-span suspension bridges under erection, Journal of Structural Engineering (2000) 14041412.

[40] H. M. Irvine, Studies in the Statics and Dynamics of Simple Cable Systems, California Institute of Technology, Technical Report, 1974.

[41] T. Theodorsen, I. E. Garrick, Nonstationary flow about a wing-aileron-tab combination including aerodynamic balance, NACA Report, TR736.

[42] L. Meirovitch, Dynamics and Control of Structures, John Wiley \& Sons, 1989.

[43] NMI Reports on the aerodynamic stability of the Humber Bridge in erection conditions, NMI, 89/0353 and 89/0361, 1977.

[44] R. H. Scanlan, J. J. Tomko, Airfoil and bridge deck flutter derivatives, Journal of Engineering Mechanics 97 (6) (1971) $1717-1737$.

[45] K. Gouder, X. Zhao, D. J. N. Limebeer, J. M. R. Graham, Experimental aerodynamic control of a long-span suspension bridge section using leading- and trailing- edge control surfaces, IEEE Transactions on Control System Technology PP, 99 (2015) 1-13.

[46] N. Martins, T. G. Lima, J. C. R. Pinto, Computing dominant poles of power system multivariable transfer functions, IEEE Transaction of Power Systems 1 (1996) 162-170.

[47] T. Kailath, Linear Systems, Prentice-Hall, 1980.

[48] M. Green, D. J. N. Limebeer, Linear Robust Control, Prentice Hall, Englewood Cliffs, New Jersey, 1995

[49] D. C. McFarlance, K. Glover, Robust Controller Design Using Normalized Coprime factor Plant Descriptions, Lecture Notes in Control and information Sciences, 138, Springer-Verlag Berlin, Heidelberg, 1990.

[50] M. Vidyasagar, Control System Synthesis: A Coprime Factorization Approach, MIT Press, 1985.

[51] K. Glover, D. McFarlane, Robust stabilization of normalized comprime factor plant descriptions with $H_{\infty}$-bounded unceratinty, IEEE TRANSACTIONS ON AUTOMATIC CONTROL 34 (1989) 821-830.

[52] R. W. Newcomb, Linear Multiport Synthesis, McGraw-Hill, 1966.

[53] M. C. Smith, Synthesis of mechanical networks: The inerter, IEEE Trans. Automatic Control 47 (10) (2002) $1648-1662$.

[54] K. N. Bakis, Active and passive aeroelastic control of long-span suspension bridges, Ph.D. thesis.

[55] P. Omenzetter, K. Wilde, Y. Fujino, Study of passive deck-flaps flutter control system on full bridge model 2: Results, Journal of Engineering Mechanics March (2002) 280-286.

\section{Appendix}

\subsection{Finite Element Matrices}

In addition to the elemental stiffness matrices for the vertical and torsional vibration case, the cable strain energy caused by the additional vibrational cable tension results in a symmetric well distributed array over the entire stiffness structure, which cannot be brought in an elemental form $[8,9]$. The equations describing the additional stiffness terms are given by the following expressions for the vertical vibration case:

$$
\mathrm{K}_{C E V}=\frac{E_{c} A_{c}}{L_{e}} \sum_{i=1}^{n_{e}}\left(\frac{W_{i}}{H}\left[f_{V}\right]_{i}\right)\left(\frac{W_{i}}{H}\left[f_{V}\right]_{i}^{T}\right)
$$

where $n_{e}$ is the number of elements, and

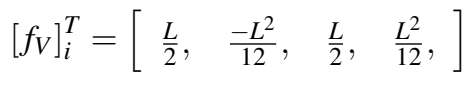

and $L_{e}$ is the virtual length given by the expression:

$$
L_{e}=L_{b}\left(1+8\left(\frac{f}{L_{b}}\right)^{2}\right)
$$

with $L_{b}$ bridge span length, $W_{i}$ Total weight per unit length and $f$ the cable sag.

Similarly, for the torsional vibration case:

$$
\mathrm{K}_{C E T}=\frac{2 E_{c} A_{c}}{L_{e}} b_{c}^{2} \sum_{i=1}^{n_{e}}\left(\frac{W_{i}}{H}\left[f_{T}\right]_{i}\right)\left(\frac{W_{i}}{H}\left[f_{T}\right]_{i}^{T}\right)
$$

where

$$
\left[f_{T}\right]_{i}^{T}=\left[\begin{array}{ll}
\frac{L}{2}, & \frac{L}{2}
\end{array}\right]
$$

In order to incorporate the flap mechanics into the FE model, additional terms related to the kinetic and potential energy of the flaps are added to the corresponding bridge terms as derived in $[8,9,10]$. These quantities are given in 
(33) and (34) respectively.

$$
\begin{gathered}
T_{l}=\frac{1}{2} \int_{A_{l}}\left[-\left(r-r_{b}\right) \dot{\beta}_{l}\right]^{2} d m \quad T_{t}=\frac{1}{2} \int_{A_{t}}\left[\left(r-r_{g a m}\right) \dot{\beta}_{t}\right]^{2} d m \\
V_{f}=\frac{1}{2} K_{\beta}\left(\beta_{l}\right)^{2}+\frac{1}{2} K_{\gamma}\left(\beta_{t}\right)^{2}
\end{gathered}
$$

For the following matrices degrees of freedom $1 . .6$ and $9 . .14$ are related to the bridge structure according to Fig.2 (b). The degrees of freedom 7,8 and 15,16 are associated with the leading and trailing edge flaps at nodes $i$ and $i+1$ of each element respectively.

\begin{tabular}{|c|c|}
\hline$K_{s}^{e}(1,1)=\frac{12 E I_{y}}{L^{3}}+\frac{36 H}{30 L}$ & $K_{s}^{e}(4,12)=K_{s}^{e}(12,4)=\frac{(2-\Phi) E I_{z}}{L}-3 L^{2} \frac{W s e L}{420 l_{h}}$ \\
\hline$K_{s}^{e}(1,2)=K_{s}^{e}(2,1)=-\frac{6 E I_{y}}{L^{2}}-\frac{3 H}{30}$ & $K_{s}^{e}(4,13)=K_{s}^{e}(13,4)=14 L \frac{W s e L}{420 l_{h}}$ \\
\hline$K_{s}^{e}(1,9)=K_{s}^{e}(9,1)=-\frac{12 E I_{y}}{L^{3}}-\frac{36 H}{30 L}$ & $\begin{array}{l}K_{s}^{e}(5,5)=140\left(1+\frac{l_{h}}{y e}\right) \frac{W s e L}{420 l_{h}}+ \\
+2 \frac{W s e L}{6 y e}+\frac{2 H}{L}+2 \frac{(W s e+W c e)}{6 y e}\end{array}$ \\
\hline$K_{s}^{e}(1,10)=K_{s}^{e}(10,1)=-\frac{6 E I_{y}}{L^{2}}-\frac{3 H}{30}$ & $K_{s}^{e}(5,11)=K_{s}^{e}(11,5)=-63 \frac{W_{s e L}}{420 l_{h}}$ \\
\hline$K_{s}^{e}(2,2)=\frac{(4+\Phi) E I_{y}}{L}+\frac{4 H L}{30}$ & $K_{s}^{e}(5,12)=K_{s}^{e}(12,5)=-14 L \frac{W s e L}{420 l_{h}}$ \\
\hline$K_{s}^{e}(2,9)=K_{s}^{e}(9,2)=\frac{6 E I_{y}}{L^{2}}+\frac{3 H}{30}$ & $\begin{aligned} K_{s}^{e}(5,13) & =K_{s}^{e}(13,5)=70\left(1+\frac{l_{h}}{y e}\right) \frac{W s e L}{420 l_{h}}- \\
& -\frac{2 H}{L}+\frac{W s e+W c e}{6 y e}+\frac{W s e L}{6 y e}\end{aligned}$ \\
\hline$K_{s}^{e}(2,10)=K_{s}^{e}(10,2)=\frac{(2-\Phi) E I_{y}}{L}-\frac{H L}{30}$ & $K_{s}^{e}(6,6)=K_{s}^{e}(14,14)=\frac{G I_{a}}{L}+\frac{36 H b_{c}^{2}}{15 L}$ \\
\hline$K_{s}^{e}(9,9)=\frac{12 E I_{y}}{L^{3}}+\frac{36 H}{30 L}$ & $K_{s}^{e}(6,14)=K_{s}^{e}(14,6)=-\frac{G I_{a}}{L}-\frac{36 H b_{c}^{2}}{15 L}$ \\
\hline$K_{s}^{e}(9,10)=K_{s}^{e}(10,9)=\frac{6 E I_{y}}{L^{2}}+\frac{3 H}{30}$ & $K_{s}^{e}(7,7)=\frac{K_{\beta} L}{2}$ \\
\hline$K_{s}^{e}(10,10)=\frac{(4+\Phi) E I_{y}}{L}+\frac{4 H L}{30}$ & $K_{s}^{e}(8,8)=\frac{K_{\gamma} L}{2}$ \\
\hline$K_{s}^{e}(3,3)=\frac{12 E I_{z}}{L^{3}}+156 \frac{W s e L}{420 l_{h}}$ & $K_{s}^{e}(11,11)=\frac{12 E I_{z}}{L^{3}}+156 \frac{W s e L}{420 l_{h}}$ \\
\hline$K_{s}^{e}(3,4)=K_{s}^{e}(4,3)=-\frac{6 E I_{z}}{L^{2}}-22 L \frac{W s e L}{420 l_{h}}$ & $K_{s}^{e}(11,12)=K_{s}^{e}(12,11)=\frac{6 E I_{z}}{L^{2}}+22 L \frac{W s e L}{420 l_{h}}$ \\
\hline$K_{s}^{e}(3,5)=K_{s}^{e}(5,3)=-147 \frac{W s e L}{420 l_{h}}$ & $K_{s}^{e}(11,13)=K_{s}^{e}(13,11)=-147 \frac{W_{s e L}}{420 l_{h}}$ \\
\hline$K_{s}^{e}(3,11)=K_{s}^{e}(11,3)=-\frac{12 E I_{z}}{L^{3}}+54 \frac{W s e L}{420 l_{h}}$ & $K_{s}^{e}(12,12)=\frac{(4+\Phi) E I_{z}}{L}+4 L^{2} \frac{W s e L}{420 l_{h}}$ \\
\hline$K_{s}^{e}(3,12)=K_{s}^{e}(12,3)=-\frac{6 E I_{z}}{L^{2}}+13 L \frac{W s e L}{420 l_{h}}$ & $K_{s}^{e}(12,13)=K_{s}^{e}(13,12)=-21 L \frac{W s e L}{420 l_{h}}$ \\
\hline$K_{s}^{e}(3,13)=K_{s}^{e}(13,3)=-63 \frac{W s e L}{420 l_{h}}$ & $\begin{array}{l}K_{S}^{e}(13,13)=140\left(1+\frac{l_{h}}{y e}\right) \frac{W s e L}{420 l_{h}}+ \\
\quad+2 \frac{W s e L}{6 y e}+\frac{2 H}{L}+2 \frac{(W s e+W c e)}{6 y e}\end{array}$ \\
\hline$K_{s}^{e}(4,4)=\frac{(4+\Phi) E I_{z}}{L}+4 L^{2} \frac{W s e L}{420 l_{h}}$ & $K_{s}^{e}(15,15)=\frac{K_{\beta} L}{2}$ \\
\hline$K_{s}^{e}(4,5)=K_{s}^{e}(5,4)=21 L \frac{W s e L}{420 l_{h}}$ & $K_{s}^{e}(16,16)=\frac{K_{\gamma} L}{2}$ \\
\hline$K_{s}^{e}(4,11)=K_{s}^{e}(11,4)=\frac{6 E I_{z}}{L^{2}}-13 L \frac{W s e L}{420 l_{h}}$ & \\
\hline
\end{tabular}

Table 5: Elemental Structural Matrices. 
Table 6: Elemental Mass Matrices.

\begin{tabular}{|c|c|}
\hline$M_{s}^{e}(1,1)=M_{s}^{e}(3,3)=156 \frac{m_{e} L}{420}$ & $M_{s}^{e}(5,5)=2 \frac{m_{c} L}{6}$ \\
\hline$M_{s}^{e}(1,2)=M_{s}^{e}(2,1)=-22 L \frac{m_{e} L}{420}$ & $M_{s}^{e}(5,13)=M_{s}^{e}(13,5)=\frac{m_{c} L}{6}$ \\
\hline$M_{s}^{e}(1,9)=M_{s}^{e}(9,1)=54 \frac{m_{e} L}{420}$ & $M_{s}^{e}(6,6)=I_{m} \frac{L}{3}$ \\
\hline$M_{s}^{e}(1,10)=M_{s}^{e}(10,1)=13 L \frac{m_{e} L}{420}$ & $M_{s}^{e}(9,9)=M_{s}^{e}(11,11)=156 \frac{m_{e} L}{420}$ \\
\hline$M_{s}^{e}(2,2)=M_{s}^{e}(4,4)=4 L^{2} \frac{m_{e} L}{420}$ & $M_{s}^{e}(9,10)=M_{s}^{e}(10,9)=22 L \frac{m_{e} L}{420}$ \\
\hline$M_{s}^{e}(2,9)=M_{s}^{e}(9,2)=-13 L \frac{m_{e} L}{420}$ & $M_{s}^{e}(10,10)=M_{s}^{e}(12,12)=4 L^{2} \frac{m_{e} L}{420}$ \\
\hline$M_{s}^{e}(2,10)=M_{s}^{e}(10,2)=-3 L^{2} \frac{m_{e} L}{420}$ & $M_{s}^{e}(11,12)=M_{s}^{e}(12,11)=M_{s}^{e}(9,10)$ \\
\hline$M_{s}^{e}(3,4)=M_{s}^{e}(4,3)=M_{s}^{e}(1,2)$ & $M_{s}^{e}(13,13)=2 \frac{m_{c} L}{6}$ \\
\hline$M_{s}^{e}(3,11)=M_{s}^{e}(11,3)=M_{s}^{e}(1,9)$ & $M_{s}^{e}(14,6)=M_{s}^{e}(6,14)=I_{m} \frac{L}{6}$ \\
\hline$M_{s}^{e}(3,12)=M_{s}^{e}(12,3)=M_{s}^{e}(1,10)$ & $M_{s}^{e}(14,14)=I_{m} \frac{L}{3}$ \\
\hline$M_{s}^{e}(4,11)=M_{s}^{e}(11,4)=M_{s}^{e}(2,9)$ & $\begin{array}{c}M_{s}^{e}(1,7)=M_{s}^{e}(7,1)=M_{s}^{e}(9,15)= \\
=M_{s}^{e}(15,9)=\frac{L}{2} S_{\beta}\end{array}$ \\
\hline$M_{s}^{e}(4,12)=M_{s}^{e}(12,4)=M_{s}^{e}(2,10)$ & $\begin{array}{c}M_{s}^{e}(1,8)=M_{s}^{e}(8,1)=M_{s}^{e}(10,16)= \\
=M_{s}^{e}(16,10)=\frac{L}{2} S_{\gamma}\end{array}$ \\
\hline$M_{s}^{e}(6,7)=M_{s}^{e}(7,6)=\frac{L}{2}\left[-\left(I_{\beta}-b c_{l} S_{\beta}\right)\right]$ & $M_{s}^{e}(14,16)=M_{s}^{e}(16,14)=\frac{L}{2}\left[\left(I_{\gamma}+b c_{t} S_{\gamma}\right)\right]$ \\
\hline$M_{s}^{e}(14,15)=M_{s}^{e}(15,14)=M_{s}^{e}(6,7)$ & $M_{s}^{e}(14,16)=M_{s}^{e}(16,14)=M_{s}^{e}(6,8)$ \\
\hline
\end{tabular}

